\title{
Article \\ Online Meeting Challenges in a Research Group Resulting from COVID-19 Limitations
}

\author{
Carol Nash (DD
}

Citation: Nash, C. Online Meeting Challenges in a Research Group Resulting from COVID-19

Limitations. Challenges 2021, 12, 29. https://doi.org/10.3390/ challe12020029

Academic Editor: Susan L. Prescott

Received: 4 October 2021

Accepted: 10 November 2021

Published: 12 November 2021

Publisher's Note: MDPI stays neutral with regard to jurisdictional claims in published maps and institutional affiliations.

Copyright: (C) 2021 by the author. Licensee MDPI, Basel, Switzerland. This article is an open access article distributed under the terms and conditions of the Creative Commons Attribution (CC BY) license (https:/ / creativecommons.org/licenses/by/ $4.0 /)$.
History of Medicine Program, Department of Psychiatry, Temerty Faculty of Medicine, University of Toronto, Toronto, ON M5S 1A1, Canada; carol.nash@utoronto.ca

\begin{abstract}
COVID-19 social distancing limitations have resulted in the utilization of hybrid online formats focused on visual contact among learners and teachers. The preferred option has been Zoom. The focus of one voluntary, democratic, self-reflective university research group-grounded in responses to writing prompts-differed. Demanding a safe space for self-reflection and creative questioning of other participants, the private Facebook group was chosen over video conferencing to concentrate on group members' written responses rather than on visual contact. A narrative research model initiated in 2015, the 2020/21 interaction of the group in the year's worth of Facebook entries, and the yearend feedback received from group participants, will be compared with previous years when the weekly group met in person. The aim is to determine the appropriateness of the online platform chosen compared with when the group met in person, pre-COVID-19, and suggest changes to improve future online group meetings. The results in relation to COVID-19 limitations indicate that an important aspect of self-directed learning related to trust arising from team mindfulness is lost when face-to-face interaction is eliminated with respect to the democratic nature of these meetings. With online meetings the new standard, maintaining trust requires improvements to online virtual meeting spaces.
\end{abstract}

Keywords: private Facebook group; COVID-19; self-directed learning; team mindfulness; democratic meetings

\section{Introduction}

The 2020-2021 academic year represented the first full year of COVID-19 restrictions to post-secondary academic meetings [1]. At one major university, where social distancing was initiated on 12 March 2020 in response to the pandemic [2], the effects of COVID19 limitations on a specific series of academic meetings can now be comprehensively interpreted. In this weekly academic offering, available yearly since 2015 through the Department of Psychiatry, the results of two consecutive terms of COVID-19 restrictions were analyzed with respect to a number of variables regarding both the ongoing meeting responses during the year and the official feedback received by participants. The variables analyzed were (1) overall participation level, (2) the types of participation, (3) the content of the participation, and (4) the products participants created. The aim of the analysis was to determine the appropriateness of the online platform chosen for conducting these academic meetings during COVID-19 and to suggest changes that might be made to these online meetings to improve participant experiences in the future as COVID-19-related restrictions to in-person meetings continue.

\subsection{COVID-19}

COVID-19 is the ongoing global pandemic identified in 2019 as severe acute respiratory syndrome coronavirus 2 (SARS-CoV-2) [3]. The World Health Organization declared COVID-19 a pandemic on 11 March 2020 [4]. As of early November 2021, over 247 million cases have been reported throughout the world, resulting in an excess of 5 million deaths [5]. 
Common symptoms include fever, cough, fatigue, shortness of breath, headache [6], loss of sense of smell [7], as well as otoneurological symptoms [8]. Complications may include pneumonia, acute respiratory distress syndrome [9] and renal failure [10]. Recommended preventive measures include hand washing, covering one's mouth when coughing, distancing from other people, wearing a face mask in public settings, disinfecting surfaces, increasing ventilation and air filtration indoors [11] and self-isolation for people who suspect they are infected [12]. Authorities worldwide responded by, among other measures, implementing lockdowns [13].

COVID-19 is thus a major health concern, both with respect to mortality and morbidity. As such, it was prudent and advisable for this major research university sponsoring the specific academic meeting here to be analyzed to cancel all academic meetings at the time it did on 12 March 2020. The advice offered by the Department of Psychiatry related to its academic meetings was to continue them via Zoom [14]. For the academic meeting to be reported on here, the facilitator proposed using a private Facebook group as an alternative- - a proposal that was accepted by the department [15].

\subsection{Choice between Online Platforms for One Particular Academic Meeting}

In relation to the use of a private Facebook group rather than the academic unit's recommendation of Zoom, the facilitator of this one specific academic meeting considered the following: (1) general criteria for determining an effective online platform for academic meetings, (2) the academic meeting's use of a private Facebook group for online communication since 2015, (3) the specific requirements for an online platform for this one academic meeting, and (4) a comparison of the relevant features of Zoom meetings and private Facebook groups pertaining to this particular academic meeting.

\subsubsection{General Criteria for Effective Online Platforms for Academic Meetings}

Academic meetings involve sharing information. Success is defined by the quality of information shared, participant satisfaction with the process, participant confidence in the outcomes and process time [16]. Success results in academic engagement, defined as the learner devoting physical and psychological energy to the academic experience [17]. By supporting social interaction, social networking sites as platforms for holding academic meetings have been found to increase meeting success [18]. They do so by facilitating learning through presenting multiple perspectives, situated learning, and transfer from instruction to real-world settings [19]. The goal of any use of online platforms for academic meetings is to be in keeping with these standards.

\subsubsection{Prior Use of a Private Facebook Group}

The uncommon academic meeting to be discussed has a history of offering the option of online meeting. To increase accessibility of the group and provide different opportunities for participation, it has always been important-pre COVID-19—-to have an online presence. The method of communicating online since 2015 has been contributing to a private Facebook group developed specifically for each academic year. With the private group, participants can view the content [20] of each meeting both synchronously during the time of the meeting and asynchronously when most convenient for them.

\subsubsection{Specific Requirements of an Online Platform}

For this particular academic meeting, digital literacy begins with building a rapport [21] with participants through a dialogue, as knowledge is considered to be distributed among participants and located within the context of activity [22]. The intent is to provide opportunities for community empowerment in addressing health inequalities [23,24].

\subsubsection{Private Facebook Groups' and Zoom's Relevant Features}

A private Facebook group is a community of Facebook users who are "friends" with at least the person who has created the private Facebook group. Only those who are part 
of the community can see what is posted to the group and add to the discussion. The private Facebook group belongs neither to the educational institution nor the participants. It belongs to the facilitator [25]. The accompanying Messenger app permits messages to be sent to Facebook friends. These two platforms work in combination. Members unable to meet at a designated time on the private Facebook group can participate either by first replying via Messenger or then in response to postings on the private Facebook group. The private Facebook group gives members the ability to access the private Facebook group at a time that is convenient for them when members may scroll through the postings of the entire academic year in using the private Facebook group. As such, there are instances when members may respond to posts months after any particular posting was originally made. It is because of the variety of options available for participation, both during the online meeting and before or after, that Facebook groups have been found engaging as a hybrid model [26]. Privacy can be an issue with inexperienced users of the Facebook platform $[27,28]$; yet an important feature of Facebook accounts with respect to privacy is that they can be created to protect user identity $[29,30]$. To maintain privacy, Facebook groups created for an academic meeting should be private as opposed to public [31].

In making the comparison between private Facebook groups and Zoom as the online platform for academic meetings, perhaps the most important difference from the point of view of participants is that Zoom, as a video conferencing platform, requires the consideration of whether or not to keep the video-the primary feature of Zoom - turned on during interactions [32]. Video conferencing has been found to present with detrimental effects on participant psyche during COVID-19 [33]. Although video online learning can create an environment similar to physical meeting space [34], and faculty struggle without visual access to participants in academic meetings [35], a norm has developed where participants opt for no video to protect their privacy and decrease their stress burden with respect to seeing themselves online [36]. With Zoom video, the focus of meeting participants tends to migrate from the topic at hand to how they and their surroundings might be evaluated in relation to others, and with respect to their own expectations of themselves [37]. Given that the major advantage of Zoom over private Facebook groups has been seen as its ability to more closely recreate the meeting environment, if the norm has become turning off the video, it is questionable whether Zoom is the appropriate choice for academic meetings when compared to private Facebook groups, especially for the group to be discussed.

\subsection{Features of Academic Meetings of Researchers}

The importance of "breaking down silos" in research communities with researchers from various disciplines becoming knowledgeable about the research of others is a growing concern in academe and has affected what is now considered important for holding successful academic meetings [38]. In creating an interdisciplinary environment, three factors are identified as relevant: self-directed learning [39], team mindfulness [40] and ensuring the meetings themselves are democratic [41].

\subsubsection{Self-Directed Learning}

Self-directed learning has been recognized as the most appropriate form of learning for adults [42] representing the core theoretical construct of the field of adult education [43]. Self-directed learning is evident when and where learners take responsibility for organizing and managing their own learning, recognizing gaps in their knowledge, critically appraising information they seek out [44], diagnosing their requirements, perceiving their goals, selecting strategies, and designing their evaluations for performances and outcomes [45]. This experience depends on learners demonstrating intrinsic motivation, integrity, agency, diligence, perseverance and grit towards their learning [46] through being continuously engaged in acquiring, applying and creating knowledge and skills in the context of their unique needs [47]. Adults are found to have a deep need to self-direct [48]. This indispensable need for learners to self-direct grew exponentially overnight as a result of the imposed COVID-19 lockdown [49]. In accordance with this deep need, the academic meeting that is 
the focus of this discussion is one that depends on and supports self-directed learning in its participants. This is because a key dimension to self-directedness is a critical awareness of meaning and self-knowledge [50], important to the process of this particular academic meeting. What is to be determined with whether the limitations presented by COVID-19 restrictions posed a challenge in the engagement of the participants in the academic meeting to embrace self-directed learning.

\subsubsection{Team Mindfulness}

Team mindfulness, with respect to how a meeting environment is constructed and maintained, has evolved to become an important consideration with respect to enhancing personal fulfilment related to work [51]—where team mindfulness is defined as a shared belief among team members that their interactions are defined by a non-judgmental awareness and an attention in processing within-team experiences [52]. This is to be done by collectively and regularly attending to the team members' experiences and their underlying objectives, tasks, roles and structures in a non-judgmental way [53]. Two of the important features of the academic meeting to be examined are its diverse membership and the continuous developmental feedback method employed. The intention is to reenergize and sustain career-long research and decrease burnout from research-related anxiety and depression. Aspects necessary for reengagement by researchers who experience burnout include the need for professional autonomy and a feeling of community based on trust with fair and equitable treatment among members [54] - all features of the team mindfulness expected of this particular academic meeting.

\subsubsection{Democratic Meetings}

Collegiality among researchers is seen as most likely to reflect a creative and productive research environment [55], yet the depression and anxiety common among researchers as a result of competition and lack of sufficient support by mentors can reduce this important collegiality [56]. Depression includes a feeling of hopelessness, helplessness, or worthlessness with respect to research endeavours [57] while anxiety in the research endeavour is characterized by caution, complaints, rumination, nervousness, and worry engaging in research tasks [58]. In contrast, researchers found to be the most productive are those who develop a certain style of thinking that includes a capacity to remain intellectually open, to play with ideas, make fine distinctions, recombine concepts and tolerate ambiguity and abstractions [59]. It is these researchers who look to colleagues as equal participants in forwarding their research pursuits rather than as competitors, with those who are most productive and fulfilled as researchers considered as the most egalitarian in their relationships with other researchers [60]. It is with the aim of reducing depression and anxiety among researchers and promoting research collegiality to aid research productivity that the type of academic meeting to be discussed was intentionally created as democratic in its aim and function.

\section{Materials and Methods}

The specific academic meeting that is the focus of this inquiry is the Health Narratives Research Group (HeNReG). It is a weekly, two-hour opportunity for university researchers ranging from undergraduates to full professors to take the personally relevant stories that initiated their commitment to health care and develop them into narratives with a particular point of view. The process includes both personal reflection and the willingness to share one's story and gain additional insights from the rest of the group. Although the level of experience differs among the researchers, for the purposes of the HeNReG, members are asked to treat each other as equals. This is a continuing, voluntary, non-credit group that meets throughout the academic year, open to any member of the university community interested in health care. Diversity of membership is sought and encouraged. A private Facebook group has been selected since 2015 for the online communication of this specific 
academic meeting. Since 12 March 2020, it has been the sole method of communication among group members.

The group is facilitated by a narrative researcher trained as a philosopher of education holding the position of a scholar in the history of medicine. The facilitator's role is similar to that of a health coach [61] or health trainer [62] for university researchers experiencing depression and/or anxiety with respect to their research careers. The group has been supported by the Department of Psychiatry at a major research university since 2015, permitting the group to meet weekly at a university hospital over the academic year pre-COVID-19.

For the 2020/21 year, the first full year of online meetings as a result of the COVID-19 pandemic, there were 20 participants in the group ranging from across the university at various stages of their academic careers, including two who resided internationally. The disciplines represented by these researchers included the following: Marketing, Pediatrics, Narrative Research (three participants), Statistical Science, Behavioural Economics, Bioinformatics, English (two participants), Social Work (two participants), Human/Computer Interaction, Neuroscience, Family Medicine (two participants), Education, Health Studies, Medicine, and East Asian Studies. These disciplines represented are compared with the representation of disciplines in each of the previous years from 2015/16 in Table 1.

Table 1. HeNReG Participants by Discipline and by Academic Year for All Six Years the Academic Meeting Has Been Sponsored by the Department of Psychiatry.

\begin{tabular}{|c|c|c|c|c|c|c|}
\hline Discipline & 2015/16 & $2016 / 17$ & 2017/18 & 2018/19 & $2019 / 20$ & $2020 / 21$ \\
\hline \multicolumn{7}{|l|}{ Humanities } \\
\hline Bioethics & 1 & 1 & & & & \\
\hline $\begin{array}{c}\text { Comparative } \\
\text { literature }\end{array}$ & 1 & 1 & & & & \\
\hline Creative writing & 3 & 1 & 2 & & & \\
\hline Critical theory & & & 1 & & & \\
\hline East Asian studies & & & & & & 1 \\
\hline English & & & 1 & 1 & 1 & 2 \\
\hline Fine art & 1 & & & & & \\
\hline History of medicine & 1 & 2 & 1 & 1 & 3 & \\
\hline Narrative research & & & 1 & 1 & 2 & 3 \\
\hline \multicolumn{7}{|l|}{ Life sciences } \\
\hline Adolescent medicine & & & 1 & & & \\
\hline Bioinformatics & & & & 1 & 1 & 1 \\
\hline Biostatistics & 1 & & & & & \\
\hline Community health & & & 1 & & 1 & \\
\hline Counselling & & & & & 1 & \\
\hline Disability studies & 1 & & & 1 & 1 & \\
\hline Exercise health & & 1 & & & & \\
\hline Family medicine & & & & & & 2 \\
\hline Global health & & & & & 2 & \\
\hline Health and safety & & & 1 & 1 & & \\
\hline Health studies & & & & & & 1 \\
\hline Immunology & & & & & 1 & \\
\hline Medical information & & & 1 & 1 & & \\
\hline Medicine & & & 2 & & & 1 \\
\hline Neuroscience & 1 & & 2 & 2 & 1 & 1 \\
\hline Nursing & & & & 1 & & \\
\hline Palliative care & & & 1 & & & \\
\hline Pediatrics & & & & & & 1 \\
\hline Pharmacy & & 1 & & & & \\
\hline Psychotherapy & & & 1 & 1 & & \\
\hline
\end{tabular}


Table 1. Cont.

\begin{tabular}{|c|c|c|c|c|c|c|}
\hline Discipline & $2015 / 16$ & $2016 / 17$ & 2017/18 & 2018/19 & $2019 / 20$ & $2020 / 21$ \\
\hline \multicolumn{7}{|l|}{ Social sciences } \\
\hline $\begin{array}{l}\text { Behavioural } \\
\text { economics }\end{array}$ & & & & & & 1 \\
\hline Diaspora studies & & & 1 & 1 & & \\
\hline Economics & & & 1 & 1 & 1 & \\
\hline Education & & & 1 & 1 & 2 & 1 \\
\hline Marketing & & 1 & & & 1 & 1 \\
\hline Psychology & & 1 & & & 1 & \\
\hline Social work & 1 & 2 & & & 3 & 2 \\
\hline Student services & & & 1 & & & \\
\hline \multicolumn{7}{|l|}{ Physical sciences } \\
\hline Chemical engineering & & & 1 & & & \\
\hline Computer science & & & & 1 & & \\
\hline Engineering & & & & 1 & & \\
\hline $\begin{array}{l}\text { Environmental } \\
\text { engineering }\end{array}$ & 1 & & & & & \\
\hline $\begin{array}{l}\text { Human/computer } \\
\text { interaction }\end{array}$ & & & & & & 1 \\
\hline Statistical sciences & & & & & & 1 \\
\hline Total of participants & 12 & 12 & 22 & 17 & 23 & 20 \\
\hline
\end{tabular}

Among these disciplines in the 2020/21 academic year, there was one undergraduate student, six graduate students, nine full-time researchers and four professors. This representation of types of researchers is compared with that of the academic years since 2015/16 in Table 2.

Table 2. HeNReG Participants by Type of Researcher in Relation to Academic Year.

\begin{tabular}{ccccccc}
\hline Type of Researcher & $\mathbf{2 0 1 5 / 1 6}$ & $\mathbf{2 0 1 6 / 1 7}$ & $\mathbf{2 0 1 7 / 1 8}$ & $\mathbf{2 0 1 8 / 1 9}$ & $\mathbf{2 0 1 9 / 2 0}$ & $\mathbf{2 0 2 0 / 2 1}$ \\
\hline Undergraduate & 3 & 4 & 7 & 6 & 9 & 1 \\
Graduate & 1 & 1 & 1 & 3 & 2 & 6 \\
Researcher * & 6 & 5 & 12 & 7 & 10 & 9 \\
Faculty & 2 & 2 & 2 & 1 & 2 & 4 \\
\hline Total & 12 & 12 & 22 & 17 & 23 & 20 \\
\hline
\end{tabular}

* Incudes research associates and amateur researchers with university affiliations.

The philosophy of the group is unique and depends on a particular interpretation of truth developed by the philosopher of education who facilitates the group. With the foundational philosophy for the group (reflected with empirical research [63]) there are two avenues to truth through research. These may be analogized to two methods of approaching a landscape with barriers.

One avenue is disciplinary [64] and sees obstacles in the landscape as barriers to eliminate by climbing higher. In disciplinary research, higher views supersede lower ones because this type of research is necessarily hierarchical. In this analogy, the purpose of discipline-based research is to create the most accurate aerial view of the landscape by overcoming and rising above the obstacles in the landscape.

In contrast, narrative research [65] describes the second method of traversing the landscape of truth. This type of research views obstacles in the landscape as landmarks to use in developing routes around these features. In narrative research, each person's point of view is considered equal and the routes created from one point of view to another are added together to complete the map of the landscape. The reason for deeming them equal is all points of view are considered necessary to view the landscape in its entirety. The purpose of narrative research in the group then is to create as many routes as possible from one point of view to another; which is why diversity is encouraged in group membership. 
This can be visualized as similar to how a "street view" is constructed in something like Google Maps [66].

From a philosophical standpoint, disciplinary research is concerned with the propositional aspect of the landscape of truth and narrative research with the ontic form of this landscape [67]. It is the collective cross-fertilization that comes from the concentration on narrative research that has been particularly fruitful for this group.

As a narrative research group based on a non-hierarchical structure, the group is also non-competitive. As a form of peer mentorship, a non-hierarchical structure has been recognized as most effective [68]. Furthermore, it is important to the group's operation that it be non-competitive as this has been shown to increase empathy towards those who are not part of the same in-group [69], a necessary component to the successful functioning of the group.

Before the lockdown, during the years when the group met at the hospital, at the beginning of each meeting the facilitator provided a pre-planned prompt for members of the group to write in response to for five minutes, without stopping or lifting their pen from the paper. The value of prompts in memory integration and self-derivation has been continually recognized and is the justification for using these prompts $[70,71]$. This type of stream of consciousness writing is a form of autoethnography [72] that has been found particularly relevant and useful in self-reflection [73]. The initial prompt provided at the first meeting of the academic year asked each person to describe themselves with respect to their research related to health. In the weeks that followed, the order of the prompts asked group members to first consider what is most objective with respect to their research related to health, then, as the weeks progressed, the prompt questions were intended to elicit answers that were increasingly subjective.

Once the lockdown was initiated, the prompts were provided the day before the online meeting via Messenger. Although the individual prompt questions have changed each year, the order of the type of questions asked remains the same: when, where, who, what, how, why. More than one session is devoted to each type of question-four weeks for the more objective questions (when, where, who and what questions) and six weeks for those questions evoking more subjective answers (how and why questions). The need for both objective and subjective questions in assessing participant's perceived relationship to their community of inquiry has been recognized by social scientists and mental health scholars [74] while the self-examination of personal stories to construct identity narratives has been recognized as giving sustainable meaning to life [75]. The order of the questions and the number of weeks they are posed is found in Table 3.

Table 3. Order of Each Type of Question Posed from the Most Objective to Most Subjective over the Weeks during the Academic Year and the Number of Weeks Each Type of Question Is the Focus.

\begin{tabular}{ccc}
\hline Rank of Question Objectivity & Order of Questions Posed & Number of Weeks Posed \\
\hline 1 & when & 4 \\
2 & where & 4 \\
3 & who & 4 \\
4 & what & 4 \\
5 & how & 6 \\
6 & why & 6 \\
\hline
\end{tabular}

Pre-COVID-19, once participants had completed their written response to the weekly prompt, each person was asked to read their response, one by one. After a participant had read their response to the prompt, each other member was given the opportunity to provide one question to the person who has just read their response to further clarify what has been read. The only requirement of the question asked was that it must begin with the same word of the week, i.e., if a "who" question was asked, each person then asked a clarifying "who" question of the reader. If a group member did not have a question, that person could choose to pass. If a group member could not think of a question right away, 
after each of the other members one at a time had provided a question, the person who had passed was given an additional opportunity to pose a question. The purpose of this was to permit those who ask the questions to see the landscape from the point of view of the reader. For the reader, the objective was to get them to revisit their point of view and picture it in greater detail. In each exchange, the development of trust was promoted. This process of weekly activities after COVID-19, which also included doodling, was modified to correspond with the online platform and can be visualized with the help of Figure 1.

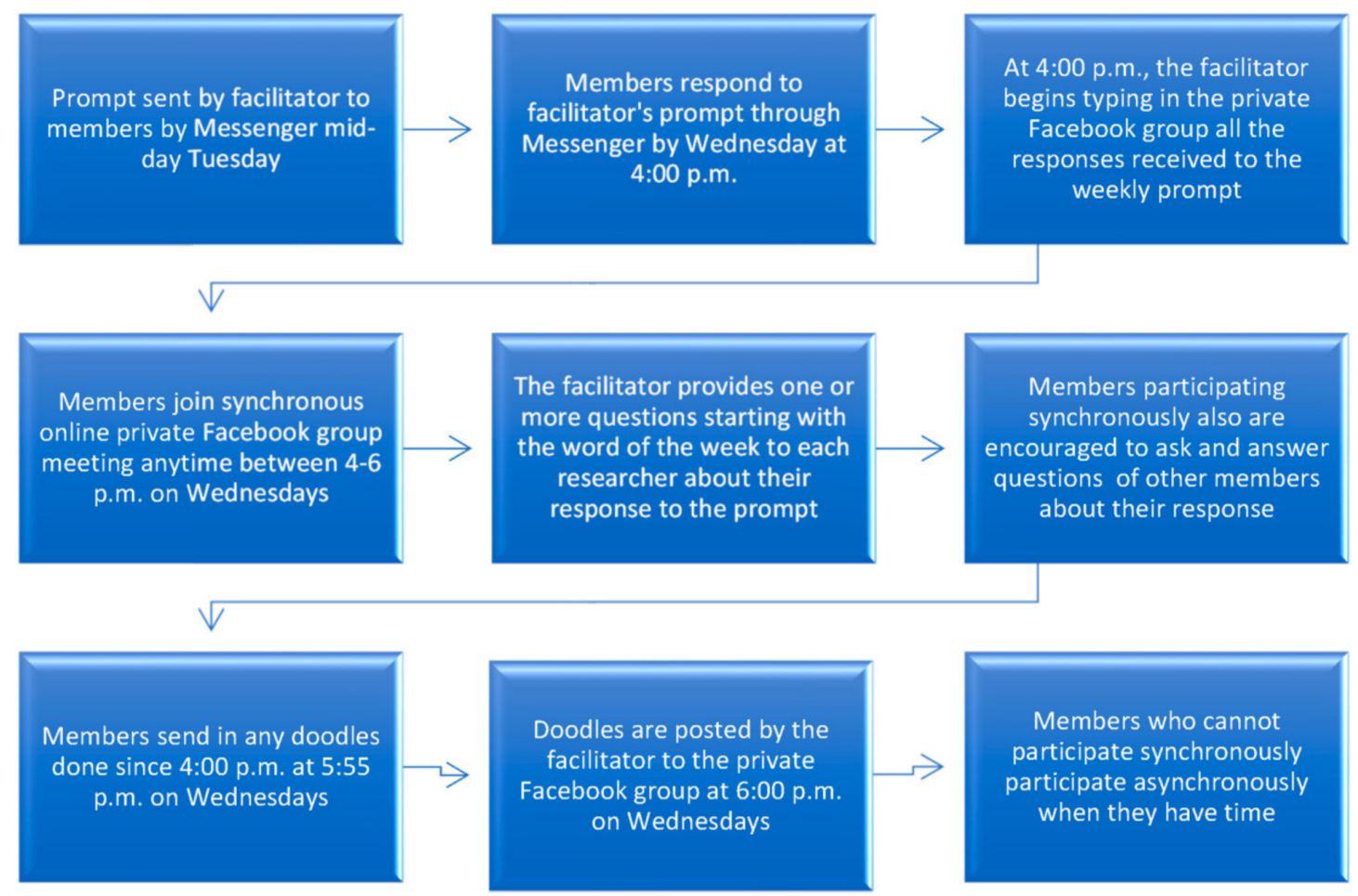

Figure 1. Weekly activities created and administered by the facilitator of the HeNReG for participants post-COVID-19 when group participation was entirely online.

The facilitator provided the group with artist's materials and paper, encouraging participants to draw or doodle during the meeting, offering an additional outlet to express their creativity. No one was required to draw. At the end of the meeting, members described their drawings or doodles one at a time going around the circle. The facilitator then noted down all the descriptions. After this, whatever was drawn, plus the written responses to the writing prompt, were collected by the facilitator to be posted to the private Facebook group to which all group members belonged from the first meeting onwards. The purpose of encouraging group members to draw or doodle is that it has been found within the group to reduce the anxiety and/or depression of those who find this situation to be a novel experience in an academic setting, helping them to concentrate more deeply on questions to ask the current reader [76]. Once the COVID-19 limitations were imposed, participants were encouraged to doodle during the two-hour weekly online meeting and to send in their doodles plus a description of the doodle to the facilitator over Messenger for posting to the private Facebook group.

One important aspect to this health-related group is that the facilitator participates in the process as an equal member [77]. As such, the facilitator both responds to the five-minute writing prompt and doodles when not recording the questions and answers of other members (in person, pre-COVID-19, and online during the pandemic). In effect, those who are part of the group see the facilitator as an additional, and equal, participant in the landscape of truth rather than as an instructor. The aim is to decrease barriers to behavioural change by having these barriers reconsidered as features in the landscape 
defining a path to reduce anxiety and depression (known to co-occur $[78,79]$ ) in the group members as much as possible.

\section{Results}

\subsection{HeNReG Activities Considered by Year}

Although the philosophy of the HeNReG has been maintained since the group became part of the Department of Psychiatry in the fall of 2015, how the group operates has changed over the years.

By the 2016/17 academic year, the HeNReG was structured in relation to its current method of asking questions in the order of those that were most objective and least likely to be anxiety provoking to those that were increasingly subjective and had a greater possibility of invoking anxiety as a result of answering the question, as a response required trust in the group members and the group process for anxiety to be mitigated. This was also the first year that drawing became an invited part of the group's activities.

During the 2017/18 academic year, the question-asking method originated the previous year was continued with different questions asked for each of the six type of prompts than used the previous year. It was clear from the results of the previous year that drawing could have a relaxing effect on participants, but only if they thought they were up to the ability level they themselves anticipated [80]. It was for this reason doodling was encouraged.

The 2018/19 academic year brought new order to the private Facebook group as the postings now included the names of all those who attended any particular meeting, including whether their attendance was synchronous or asynchronous. Doodling became a regular feature of the group.

2019/20 was not only the academic year that was interrupted by the COVID-19 lockdown, requiring that what was previously conceived as an in-person academic meeting become one that was entirely online, it also was the year that the HeNReG adopted its continuing method in all respects. Regarding the private Facebook group, the entries now began with the first name of the participant as a heading and, on the line below, the date was listed. What followed was the names of the people who participated that particular day, the person's response to the prompt and any questions they received. The major change of group was moving from in-person meetings in the hospital's occupational therapy room to online meetings, with both a synchronous and asynchronous component on the private Facebook group, as a result of the COVID-19 lockdown mid-March. Now, any doodles initiated by group members on their own were dependent on the participant already having their personally sought-after materials with which to doodle.

The various features of the HeNReG over each of the six year of its operation are outlined in Table 4 with respect to whether or not any year had a particular feature.

Table 4. Features of the HeNReG over its Six Years of Operation.

\begin{tabular}{|c|c|c|c|c|c|c|}
\hline Feature of the HeNReG & $2015 / 16$ & $2016 / 17$ & $2017 / 18$ & $2018 / 19$ & $2019 / 20$ & $2020 / 21$ \\
\hline Called the Health Narratives Research Group & No & Yes & Yes & Yes & Yes & Yes \\
\hline Used method of question asking & No & Yes & Yes & Yes & Yes & Yes \\
\hline Posts on private Facebook group ordered by date & No & Yes & Yes & Yes & Yes & Yes \\
\hline $\begin{array}{c}\text { Posts on private Facebook group ordered by participant } \\
\text { name }\end{array}$ & Yes & Yes & No & No & Yes & Yes \\
\hline Posts on private Facebook group ordered by number & No & No & No & Yes & No & No \\
\hline List of attendees posted on private Facebook group & No & No & No & Some & Yes & Yes \\
\hline Doodling encouraged from the beginning of the year & No & No & No & Yes & Yes & Yes \\
\hline $\begin{array}{l}\text { Meetings entirely online using the private Facebook } \\
\text { group }\end{array}$ & No & No & No & No & A few & Yes \\
\hline
\end{tabular}

\subsection{Participation during the Most Recent Three Years of the HeNReG}

Participation in the HeNReG was in a number of forms. That which most group members responded to was participating in answering the weekly prompts provided the 
day before the meeting via Messenger. The second form of participation was attending the weekly two hour meeting. At the meeting, group members each participated in answering questions asked of them in relation to their response to the writing prompt. Members could decide whether or not they wanted to ask a question of another participant, representing another level of participation. Group members could also decide whether or not to doodle while at the meeting. An additional form of participation was responding to questions asked during the meeting asynchronously if the group member had not attended the meeting. Asking questions online of others was then a further form of participation. The last form of participation was merely looking at what was posted online without making any comment. How many members actually visited the private Facebook group to just look at what had been posted was information visible only to the facilitator, the private Facebook group account holder. Table 5 outlines each of these different forms of participation in the order they could take place each week.

Table 5. Forms of Participation in the Health Narratives Research Group by Order in Which They Would Take Place Weekly during the Academic Year.

\begin{tabular}{cc}
\hline Order & Form of Participation \\
\hline 1 & Responding to the weekly writing prompts sent via Messenger \\
2 & Answering questions at the synchronous weekly meeting \\
3 & Asking questions of others at the synchronous weekly meeting \\
4 & Creating and describing doodles at the synchronous weekly meeting \\
5 & Answering one's questions on the private Facebook group asynchronously \\
6 & Asking others questions on the private Facebook group asynchronously \\
7 & Looking at postings on the private Facebook group asynchronously \\
\hline
\end{tabular}

Given that the organization and delivery of the HeNReG has not remained static since 2015, and because some of the changes entail that the year by year results are not truly comparable, the outcome of the full year of the lockdown, 2020/21, will be compared in detail with only the two years that preceded it—2018/19 and 2019/20—after the group obtained its present form. The comparison will be by week, total number of participants, synchronous participation, asynchronous participation and the number of drawings received to be posted. Table 5 provides this comparison with respect to total participation, the participation broken into synchronous and asynchronous and the drawings that were received from participants for the full academic year. For a member to be counted as participating, the member at the very least responded to the weekly writing prompt. Merely looking at the postings on the private Facebook group is not counted as participating if this were the only method of participation as such participation was visible only to the facilitator, not to the group as a whole.

In examining the average participation of group members throughout the year in each of the three years, it appears on the surface that the average number of participants in total increased each year. Yet, recalling Tables 1 and 2, the total number of participants in 2018/19 was 17, for 2019/20 it was 23 and, in relation to 2020/21, the participants numbered 20. This means that in actuality the total participation, although greatest in the most recent year, actually went down in the second year when the group had the largest number of participants. The reason for this lessening of participation towards the end of the second term was not investigated.

Regarding the synchronous participation, it is clear from Table 6 that, at the very most, only half of the group members ever attended the group synchronously-either in person or online once the group met on the private Facebook group. Often the number who met synchronously was a quarter of the group participants. It is notable that the number who met synchronously was not greatly affected by the fact of moving the group online after 12 March 2020. 
Table 6. Response to the Weekly Writing Prompts in Total Participation, Synchronous Participation and Asynchronous Participation Plus Response to the Weekly Requests for Doodles in Drawings Created during the Health Narratives Research Group, Both in Person and Online (Through the Private Facebook Group), over the Three Most Recent Academic Years.

\begin{tabular}{|c|c|c|c|c|c|c|c|c|c|c|c|c|}
\hline \multirow{2}{*}{$\begin{array}{l}\text { Week of } \\
\text { Meeting }\end{array}$} & \multicolumn{3}{|c|}{ Total Participation } & \multicolumn{3}{|c|}{ Synchronous } & \multicolumn{3}{|c|}{ Asynchronous } & \multicolumn{3}{|c|}{ Drawings Created } \\
\hline & 2018/19 & $2019 / 20$ & $2020 / 21$ & 2018/19 & $2019 / 20$ & $2020 / 21$ & 2018/19 & $2019 / 20$ & $2020 / 21$ & 2018/19 & $2019 / 20$ & $2020 / 21$ \\
\hline 1 & 12 & 12 & 16 & 8 & 7 & 10 & 4 & 5 & 6 & 12 & 11 & 3 \\
\hline 2 & 7 & 15 & 17 & 5 & 5 & 10 & 2 & 10 & 7 & 4 & 5 & 4 \\
\hline 3 & 13 & 16 & 15 & 6 & 8 & 7 & 7 & 8 & 8 & 7 & 10 & 3 \\
\hline 4 & 11 & 14 & 15 & 6 & 9 & 6 & 5 & 5 & 9 & 11 & 10 & 5 \\
\hline 5 & 14 & 15 & 16 & 5 & 7 & 5 & 9 & 8 & 11 & 7 & 9 & 6 \\
\hline 6 & 11 & 14 & 16 & 3 & 4 & 9 & 8 & 9 & 7 & 4 & 5 & 4 \\
\hline 7 & 12 & 15 & 17 & 5 & 7 & 7 & 7 & 8 & 10 & 5 & 10 & 2 \\
\hline 8 & 12 & 16 & 15 & 4 & 6 & 6 & 8 & 10 & 9 & 7 & 12 & 5 \\
\hline 9 & 12 & 14 & 16 & 2 & 7 & 4 & 10 & 7 & 12 & 2 & 9 & 2 \\
\hline 10 & 13 & 14 & 14 & 5 & 4 & 6 & 6 & 10 & 8 & 8 & 4 & 2 \\
\hline 11 & 12 & 11 & 16 & 5 & 7 & 4 & 7 & 4 & 12 & 6 & 11 & 1 \\
\hline 12 & 10 & 11 & 13 & 4 & 3 & 10 & 6 & 8 & 3 & 6 & 3 & 4 \\
\hline 13 & 12 & 11 & 15 & 6 & 3 & 9 & 6 & 8 & 6 & 8 & 5 & 4 \\
\hline 14 & 12 & 16 & 13 & 4 & 6 & 8 & 8 & 10 & 5 & 5 & 16 & 3 \\
\hline 15 & 14 & 14 & 15 & 7 & 4 & 9 & 7 & 10 & 6 & 4 & 6 & 4 \\
\hline 16 & 12 & 16 & 17 & 3 & 7 & 8 & 9 & 9 & 9 & 4 & 17 & 2 \\
\hline 17 & 12 & 13 & 15 & 3 & 3 & 10 & 9 & 10 & 5 & 6 & 6 & 4 \\
\hline 18 & 13 & 14 & 12 & 4 & 8 & 7 & 9 & 6 & 5 & 4 & 12 & 2 \\
\hline 19 & 11 & 12 & 13 & 4 & 2 & 5 & 7 & 10 & 8 & 9 & 4 & 1 \\
\hline 20 & 12 & 15 & 11 & 3 & 5 & 6 & 9 & 11 & 5 & 3 & 6 & 2 \\
\hline 21 & 12 & 13 & 13 & 5 & 5 & 6 & 7 & 8 & 7 & 7 & 7 & 2 \\
\hline 22 & 12 & 12 * & 12 & 4 & $5 *$ & 8 & 8 & $7 *$ & 4 & 5 & $2 *$ & 2 \\
\hline 23 & 11 & 17 & 12 & 4 & 6 & 6 & 7 & 11 & 8 & 9 & 3 & 3 \\
\hline 24 & 10 & 13 & 12 & 5 & 4 & 5 & 5 & 9 & 7 & 9 & 4 & 1 \\
\hline 25 & 10 & 13 & 12 & 3 & 4 & 8 & 7 & 9 & 4 & 3 & 2 & 4 \\
\hline 26 & 12 & 12 & 11 & 7 & 4 & 6 & 5 & 8 & 5 & 9 & 2 & 2 \\
\hline 27 & 11 & 11 & 13 & 6 & 6 & 7 & 5 & 5 & 6 & 8 & 3 & 2 \\
\hline 28 & 12 & 12 & 13 & 6 & 4 & 8 & 6 & 8 & 5 & 7 & 5 & 3 \\
\hline Average & 11.68 & 12.36 & 14.11 & 4.71 & 5.36 & 7.14 & 6.68 & 7.96 & 7.04 & 6.39 & 7.11 & 2.93 \\
\hline Percent & 68.71 & 53.74 & 70.55 & 27.70 & 23.30 & 36 & 39.29 & 34.61 & 35.20 & 37.59 & 30.91 & 14.65 \\
\hline
\end{tabular}

* From week 22, 2020, and throughout 2021, all meetings (both synchronous and asynchronous) conducted online rather than in person as a result of COVID-19 limitations.

Before the pandemic, group participants preferred meeting asynchronously rather than synchronously. This is likely for one of two reasons: the group met in person at a downtown hospital-and for many participants, meeting at the hospital was prohibitive, both in time and distance; furthermore, the group met from 4:00 p.m. to 6:00 p.m. when a number of the group participants were still at their place of employment and unable to attend. Yet, once the group only met online, some group members who had claimed they wanted to meet synchronously (but because the time and distance to travel did not) still preferred to meet asynchronously. These group members then demonstrated feeling most comfortable with meeting asynchronously. Slightly more people during the pandemic year participated synchronously than asynchronously.

Where the biggest change was evident in comparing the three academic years is with respect to drawings submitted. When the group met in person, the facilitator provided participants with paper and drawing materials to doodle. In other words, not only were the group members verbally encouraged to doodle, they were also given the means to do so. As well, many of the art materials that were presented by the facilitator to the group were considered by them to be attractive. While doodling in person pre-COVID-19, participants would often mention they were doodling because they wanted to try various artist's materials [80]. In contrast, when they participated online from home, some group 
members may not have had artist's materials and, thus, one of the reasons for them for creating the doodle was lost. Another reason is that some saw doodling as a cooperative effort that was not available to them when they doodled on their own.

What Table 6 does not reveal is the amount of participation that was generated with respect to asking questions of other members and participants answering these questions. This is evident from Table 7.

Table 7. Total Number of Questions Asked and the Number of People Posing Questions, Those Doing So Synchronously during the Health Narratives Research Group Meeting (Pre-COVID-19 in Person, after 12 March 2021, Online), and Those Asking and Answering Asynchronously through the Private Facebook Group, over the Three Most Recent Academic Years.

\begin{tabular}{|c|c|c|c|c|c|c|c|c|c|c|c|c|c|c|c|c|c|c|}
\hline \multirow{3}{*}{$\begin{array}{c}\text { Week of } \\
\text { Meeting }\end{array}$} & \multicolumn{6}{|c|}{$\begin{array}{l}\text { Total Questions Asked and } \\
\text { Number of People Asking }\end{array}$} & \multicolumn{6}{|c|}{$\begin{array}{c}\text { Synchronous Questions Asked } \\
\text { and Answered }\end{array}$} & \multicolumn{6}{|c|}{$\begin{array}{c}\text { Asynchronous Questions Asked } \\
\text { and Answered }\end{array}$} \\
\hline & \multicolumn{2}{|c|}{$2018 / 19$} & \multicolumn{2}{|c|}{$2019 / 20$} & \multicolumn{2}{|c|}{$2020 / 21$} & \multicolumn{2}{|c|}{$2018 / 19$} & \multicolumn{2}{|c|}{$2019 / 20$} & \multicolumn{2}{|c|}{$2020 / 21$} & \multicolumn{2}{|c|}{$2018 / 19$} & \multicolumn{2}{|c|}{$2019 / 20$} & \multicolumn{2}{|c|}{$2020 / 21$} \\
\hline & 37 & 7 & 74 & 7 & 54 & 8 & 33 & 29 & 62 & 37 & 54 & 33 & 4 & 0 & 12 & 19 & 0 & 0 \\
\hline 2 & 33 & 7 & 71 & 5 & 74 & 8 & 26 & 16 & 71 & 21 & 74 & 47 & 7 & 6 & 0 & 20 & 0 & 2 \\
\hline 3 & 62 & 6 & 112 & 8 & 61 & 9 & 61 & 26 & 102 & 49 & 53 & 32 & 1 & 10 & 10 & 25 & 8 & 0 \\
\hline 4 & 59 & 6 & 118 & 9 & 61 & 7 & 59 & 29 & 115 & 64 & 61 & 21 & 0 & 22 & 3 & 6 & 0 & 0 \\
\hline 5 & 72 & 6 & 115 & 7 & 44 & 4 & 71 & 19 & 95 & 36 & 44 & 8 & 1 & 14 & 20 & 33 & 0 & 7 \\
\hline 6 & 37 & 3 & 49 & 5 & 57 & 7 & 35 & 11 & 48 & 12 & 57 & 30 & 2 & 3 & 1 & 21 & 0 & 7 \\
\hline 7 & 54 & 5 & 96 & 8 & 85 & 11 & 53 & 18 & 86 & 46 & 83 & 33 & 1 & 20 & 10 & 23 & 2 & 1 \\
\hline 8 & 44 & 4 & 100 & 8 & 53 & 5 & 34 & 11 & 84 & 31 & 53 & 21 & 10 & 15 & 16 & 18 & 0 & 3 \\
\hline 9 & 43 & 3 & 89 & 8 & 70 & 6 & 36 & 5 & 79 & 38 & 70 & 24 & 7 & 10 & 10 & 12 & 0 & 2 \\
\hline 10 & 43 & 5 & 75 & 7 & 59 & 7 & 42 & 18 & 53 & 12 & 59 & 23 & 1 & 7 & 22 & 10 & 0 & 6 \\
\hline 11 & 50 & 5 & 73 & 9 & 48 & 4 & 43 & 15 & 65 & 37 & 48 & 12 & 7 & 15 & 8 & 21 & 0 & 0 \\
\hline 12 & 36 & 4 & 39 & 4 & 63 & 7 & 35 & 12 & 36 & 10 & 32 & 25 & 1 & 0 & 3 & 1 & 31 & 4 \\
\hline 13 & 57 & 6 & 37 & 4 & 75 & 7 & 55 & 23 & 33 & 11 & 62 & 32 & 2 & 5 & 4 & 8 & 13 & 3 \\
\hline 14 & 47 & 4 & 86 & 7 & 50 & 6 & 46 & 12 & 78 & 22 & 50 & 17 & 1 & 9 & 8 & 7 & 0 & 0 \\
\hline 15 & 71 & 7 & 49 & 4 & 44 & 4 & 65 & 37 & 49 & 15 & 42 & 14 & 6 & 12 & 0 & 6 & 2 & 0 \\
\hline 16 & 30 & 3 & 70 & 8 & 39 & 4 & 30 & 6 & 63 & 35 & 39 & 15 & 0 & 6 & 7 & 1 & 0 & 0 \\
\hline 17 & 33 & 3 & 58 & 5 & 51 & 5 & 33 & 6 & 45 & 11 & 51 & 23 & 0 & 3 & 13 & 4 & 0 & 0 \\
\hline 18 & 49 & 4 & 100 & 10 & 55 & 5 & 49 & 13 & 92 & 50 & 52 & 30 & 0 & 4 & 8 & 1 & 3 & 0 \\
\hline 19 & 37 & 4 & 37 & 4 & 46 & 3 & 37 & 12 & 26 & 6 & 46 & 26 & 0 & 9 & 11 & 3 & 0 & 0 \\
\hline 20 & 37 & 3 & 72 & 5 & 45 & 5 & 37 & 6 & 72 & 21 & 44 & 23 & 0 & 3 & 0 & 11 & 1 & 0 \\
\hline 21 & 54 & 5 & 63 & 5 & 39 & 4 & 54 & 16 & 63 & 26 & 39 & 18 & 0 & 3 & 0 & 5 & 0 & 0 \\
\hline 22 & 40 & 4 & $\begin{array}{c}36 \\
*\end{array}$ & $4^{\ddagger}$ & 29 & 3 & 40 & 12 & $\begin{array}{c}33 \\
*\end{array}$ & $6^{\ddagger}$ & 28 & 10 & 0 & 3 & $3 *$ & $7 \ddagger$ & 1 & 0 \\
\hline 23 & 40 & 4 & 53 & 5 & 36 & 3 & 40 & 12 & 53 & 19 & 36 & 20 & 0 & 7 & 0 & 0 & 0 & 0 \\
\hline 24 & 35 & 5 & 24 & 4 & 13 & 1 & 35 & 17 & 24 & 8 & 13 & 3 & 0 & 3 & 0 & 0 & 0 & 0 \\
\hline 25 & 30 & 3 & 31 & 4 & 53 & 5 & 27 & 8 & 31 & 6 & 50 & 33 & 3 & 2 & 0 & 0 & 3 & 8 \\
\hline 26 & 66 & 7 & 28 & 3 & 34 & 3 & 65 & 34 & 28 & 7 & 30 & 15 & 1 & 7 & 0 & 0 & 4 & 0 \\
\hline 27 & 68 & 6 & 23 & 4 & 38 & 3 & 68 & 32 & 23 & 13 & 38 & 19 & 0 & 0 & 0 & 0 & 0 & 2 \\
\hline 28 & 65 & 6 & 20 & 2 & 38 & 3 & 65 & 26 & 20 & 4 & 38 & 21 & 0 & 0 & 0 & 0 & 0 & 2 \\
\hline$\S$ Ave/week & 47 & 5 & 64 & 6 & 51 & 5 & 46 & 17 & 58 & 23 & 48 & 22 & 2 & 7 & 6 & 9 & 2 & 2 \\
\hline${ }^{+}$Ave/Part. & 2.8 & 28 & 2.8 & 25 & 2.5 & 26 & 2.7 & 1.0 & 2.5 & 1.0 & 2.4 & 1.1 & 0.1 & 0.4 & 0.3 & 0.4 & 0.1 & 0.1 \\
\hline
\end{tabular}

${ }^{*}$ From week 22, 2020, and throughout 2021, all questions asked online (both synchronously and asynchronously) rather than in person as a result of COVID-19 limitations. $\ddagger$ From week 22, 2020, and throughout 2021, all questions answered online (both synchronously and asynchronously) rather than in person as a result of COVID-19 limitations. ${ }^{\S}$ Average per week calculated in whole numbers. Average per participant calculated to one decimal place. ${ }^{\dagger}$ The three numbers in bold on the Average per participant line, under number of people asking, represent the percentage of participants who asked questions in any week for the three years represented, not the average.

During the time the HeNReG met in person, before mid-March 2020, everyone at the meeting was asked by the facilitator to provide a question to all participants in relation to each person's five-minute stream of consciousness writing in response to the weekly prompt. Although some people might pass-and this was an acceptable practice-it was unusual for any group member not to ask another participant a question. In other words, every group member of those present asked every other one a question with respect to their response to the prompt. When the group met online, this changed. Online, group members would choose to ask questions of only a few of the participants. As well, some people's 
responses to the prompt would elicit very few questions while other responses would get many more. It is quite possible that fewer people began to attend synchronously in 2021 after the first few weeks because they were not getting questions from many participants. However, whether this was actually the case was not tested.

What is interesting is that although question-asking changed once the group met entirely online, the average number of questions per each participant remained constant over the three years with the average percentage of group members asking questions any particular week being $28 \%$ the first year, $25 \%$ the second and $26 \%$ the third. The most notable change once the pandemic marshalled the group online is in those questions asked and answered asynchronously. Very few participants who would go to the group asynchronously would either ask a question of others or answer the questions that others had posed to them. Yet, this lack of asking or answering questions did not decrease their weekly participation in responding to the writing prompt (as seen by the total participation from Table 6).

It is quite possible that the reason for this diminished participation was COVID-19 related-researchers wanted to continue with the group but felt they had a limited amount of energy to invest. Yet, there may have been a number of reasons why participants did not choose to attend synchronously any particular week as there was no requirement that members attend and there was no financial loss to not attending. This type of information was not evident in assessing the number of questions asked and the number of people posing questions. How the group members did assess their participation is apparent with an examination of the written responses to the yearend feedback forms, next to be highlighted.

\subsection{Feedback during the Most Recent Three Years of the HeNReG}

Feedback forms were provided to participants of the HeNReG online twice yearly: at the end of the calendar year in December and at the end of the academic year in April. The form that was provided for feedback is one common to all offerings of the Health, Arts and Humanities program through the Department of Psychiatry of which the HeNReG is among. The primary purpose of the form is to give participants the opportunity to reflect on the experience of undergoing the process of narrative research encouraged by the group. Three of the questions asked on the form allow for extended written responses. It is these detailed responses that provide direct insight into the experience participants had with respect to the group. What is to be presented for comparison is the April feedback responses for each of the 2018/19, 2019/20 and 2020/21 academic years regarding these three questions-How was the group valuable to you as a researcher? How might the HeNReG be of help to you in the future? Do you have other thoughts/comments on your experience as a participant in the HeNReG this term, especially as a result of COVID-19? The results will be provided consecutively in each of Tables 8-10. In these tables, the responses are listed as they were received by the facilitator when the forms were returned. In certain cases, though, the response offered by one participant included mention of more than one theme. When this occurred, each theme mentioned was recorded. Therefore, the listing of the theme in these cases took precedent over indicating the order in which the form was returned.

With respect to Table 8, the responses provided to "How was the group valuable to you as a researcher?" were quite similar in each of the three years, although 2018/19 had in-person meetings throughout the year, 2019/20 was interrupted by the COVID19 lockdown mid-March 2020, and 2020/21 was entirely online. In these three years, the primary responses were that the HeNReG (1) encouraged self-refection on research, (2) provided the perspectives of other researchers and (3) gave a safe place to verbalize ideas about research. Secondarily, participants from all three years thought the HeNReG challenged their thinking about research. Since the same questioning structure was used in every one of these years and only participants from the two most recent years mentioned the HeNReG presenting a useful and easily employed structure for asking questions, it is 
possible that the response by two members in the first year-that the HeNReG invited a broader view of research-pertains to the question-asking structure. This is possible as, similarly, no participant in either of the most recent two years mentioned the importance of a broader view of research per se. These responses provided by the participants were found to be of the same degree that would have been anticipated by the facilitator in participants providing feedback about the group.

Table 8. Themes Mentioned in Responses Provided on the April Feedback Forms to How Was the Group Valuable to You as a Researcher? For Each of the Three Most Recent Academic Years in Order of Receipt of Feedback Forms from Group Members.

\begin{tabular}{|c|c|c|c|}
\hline Themes Mentioned in Feedback Forms & $\begin{array}{l}2018 \\
2019\end{array}$ & $\begin{array}{l}2019 \\
2020\end{array}$ & $\begin{array}{l}2020 \\
2021\end{array}$ \\
\hline Enhanced my work as a narrative researcher & 1 & & \\
\hline Encouraged self-reflection on research & 4 & 4 & 5 \\
\hline Provided the perspectives of other researchers & 4 & 3 & 4 \\
\hline Helped in greater understanding of one's research & 2 & 1 & \\
\hline Sharpened thinking about research & 2 & 2 & 1 \\
\hline Invited a broader view of research & 3 & & \\
\hline Gave a safe space to verbalize ideas about research & 1 & 4 & 4 \\
\hline Challenged my thinking about research & 1 & 1 & 2 \\
\hline Restfully cleared my thoughts regarding my research & & 2 & \\
\hline Determined the direction I should go in my research & & 1 & \\
\hline Presented a useful and easily employed structure for asking questions & & 2 & 1 \\
\hline Reoriented my priorities regarding my research & & 1 & \\
\hline Engaged my curiosity and focus & & 2 & \\
\hline Offered a way to access my drives and motivations related to research & & 1 & \\
\hline Allowed for a comparison of ideas with previous years of this group & & & 1 \\
\hline Sorted out my problems with my research & & 1 & 1 \\
\hline Decreased barriers in research & & & 1 \\
\hline Tailored the understanding of research to the researcher & & & 2 \\
\hline Shared valuable resources & & & 1 \\
\hline Reminded me of what is important and valuable in my research & & & 1 \\
\hline Provided community and accountability in research & & & 1 \\
\hline Motivated and inspired me with respect to my research & & & 1 \\
\hline Learned more about self-expression & & & 1 \\
\hline
\end{tabular}

Table 9 provides the responses participants gave to the question How might the HeNReG be of help to you in the future? The most frequent reply was it helped by using the structure of the weekly prompts to guide their self-reflection. Since the most unique aspect of the group differing it from other health-humanities offerings was the structure created for question asking, it is important to note that this structure was mentioned in all three years as potentially helpful by the greatest number of people. Three other comments regarding how the HeNReG might be helpful in the future were made by at least one participant each year: (1) Offering different points of view, (2) Decreasing my confusion about what should be my focus in my research, and (3) Keeping me updated on interesting topics in various fields. Given that it was considered important to the success of the group for it to include members from diverse backgrounds and have the ability to help reduce depression and anxiety with respect to their research, that participants would mention these aspects of the HeNReG might help the participants in the future was in line with the intention of the program. 
Table 9. Themes Mentioned in Responses Provided on the April Feedback Forms to How Might the HeNReG be of Help to You in the Future? For Each of the Three Most Recent Academic Years in Order of Receipt of Feedback Forms from Group Members.

\begin{tabular}{|c|c|c|c|}
\hline Themes Mentioned in Feedback Forms & $\begin{array}{l}2018 \\
2019\end{array}$ & $\begin{array}{l}2019 \\
2020\end{array}$ & $\begin{array}{l}2020 \\
2021\end{array}$ \\
\hline Offering different points of view & 1 & 1 & 1 \\
\hline Opening up discussion & 1 & & \\
\hline Meeting additional interesting participants & 1 & & 2 \\
\hline Using the structure of weekly prompts to guide my self-reflection & 1 & 4 & 5 \\
\hline Decreasing my confusion about what should be my focus in my research & 1 & 2 & 1 \\
\hline Sharing resources & 1 & & 1 \\
\hline Making me more open minded & 1 & 1 & \\
\hline Permitting me to grow as a researcher & 1 & & 1 \\
\hline Listening to others and giving feedback & 1 & & \\
\hline Keeping me updated on interesting topics in various fields & 1 & 1 & 1 \\
\hline Encouraging more collaborative artistic creation in my research & 1 & & 1 \\
\hline Understanding and respecting different points of view & 1 & & 1 \\
\hline Continuing with creative reflection & 1 & & \\
\hline Helping me plan my research & 1 & & 1 \\
\hline Expanding my research to other fields & & 2 & 1 \\
\hline Increasing my confidence as a researcher & & 1 & \\
\hline Learning more about various ways of expressing oneself creatively & & 1 & \\
\hline Practicing writing & & 1 & \\
\hline Going on with my research & & 1 & 3 \\
\hline Continuing as part of the group in future years & & 1 & \\
\hline Coping with life challenges regarding my research & & 1 & \\
\hline Reminding me to construct a narrative that drives my work & & 1 & \\
\hline Acting as a sounding board & & 1 & 1 \\
\hline Supporting network connections & & & 2 \\
\hline Clarifying what I value regarding my research & & & 2 \\
\hline Providing a comparison of results of the group over a number of years & & & 1 \\
\hline Including Zoom meetings & & & 1 \\
\hline Being a supportive community in a safe space & & & 2 \\
\hline
\end{tabular}

Table 10 concerns answers to the question Do you have other thoughts/comments on your experience as a participant in the HeNReG this term? In the most recent two years, after COVID-19 moved the group entirely online, "(especially as a result of COVID-19)" was added to the question. There was only one response that was common to all three years: I liked the option of participating remotely, I didn't have to travel. This response corresponds to what was found regarding the use made of online participation by group members evident in Table 6. It is remarkable that even when participants were specifically prompted to give their opinions related to the how COVID-19 affected their participation in the group, there were only three references to COVID-19-two expressing they hoped COVID-19 ended soon and only one indicating that COVID-19 had directly affected their ability to participate. One group member mentioned that the HeNReG got them engaged during the lockdown. In that there were more group members whose participation was affected by COVID-19, it is worth noting that thoughts of the pandemic were not foremost in their mind when providing their additional comments.

Once the group's meetings were entirely online in the second year and throughout the most recent year, some group members were aware that the participation in the group changed. Participants either noted their own decrease in attending or that the group as a whole had less participation (even though, in actuality, the participation was comparable to when the group met in person). Exhaustion and/or isolation, both problems mentioned, might be reasons why participants felt that there was less participation in the HeNReG than they anticipated. 
Table 10. Themes Mentioned in Responses Provided on the April Feedback Forms to Do You Have Other Thoughts/Comments on Your Experience as a Participant in the HeNReG this Term (Especially as a Result of COVID-19) for Each of the Three Most Recent Academic Years in Order of Receipt of Feedback Forms from Group Members.

\begin{tabular}{|c|c|c|c|}
\hline Themes Mentioned in Feedback Forms & $\begin{array}{l}2018 \\
2019\end{array}$ & $\begin{array}{l}2019 \\
2020\end{array}$ & $\begin{array}{l}2020 \\
2021\end{array}$ \\
\hline This is a good program & 1 & & \\
\hline A wonderful experience & 1 & & \\
\hline I love this group! & 1 & & 1 \\
\hline I liked the option of participating remotely, I didn't have to travel & 1 & 2 & 3 \\
\hline I would like to try to not use prompts & 1 & & \\
\hline It would be good to have some exercises related to writing and art & 1 & & \\
\hline Drawing is so helpful to get my mind thinking differently & 1 & & \\
\hline $\begin{array}{l}\text { I wish I could come to the meetings more, but the group is } \\
\text { in the workday }\end{array}$ & 1 & & 2 \\
\hline Moving online was a smooth transition & & 2 & \\
\hline I am thankful to express myself in a non-judgmental environment & & 1 & \\
\hline The people brought together in this group are amazing & & 1 & \\
\hline I love learning about other fields of research & & 1 & \\
\hline The group is easily accessible for people with scheduling problems & & 1 & \\
\hline Thank you! & & 3 & 1 \\
\hline I love the doodling aspect and seeing people's doodles & & 2 & \\
\hline Maybe we could include video chatting & & 1 & 1 \\
\hline Having a designated meeting time makes me take time to self-reflect & & 1 & \\
\hline I miss the personal interaction now that everything is online & & 1 & 2 \\
\hline $\begin{array}{l}\text { I had expected this was a creative writing group, but I easily } \\
\text { shifted focus }\end{array}$ & & 1 & \\
\hline I hope COVID-19 ends soon & & & 2 \\
\hline Switching to online decreased the amount that people doodled & & & 1 \\
\hline $\begin{array}{l}\text { Fewer people responded to questions asked when we were } \\
\text { entirely online }\end{array}$ & & & 1 \\
\hline I like the flexibility and structure of the group & & & 2 \\
\hline The year has been very isolating, this group was a great way to network & & & 2 \\
\hline COVID-19 affected my ability to participate & & & 1 \\
\hline $\begin{array}{l}\text { I'm glad we did not use the videoconferencing format; it's } \\
\text { too exhausting }\end{array}$ & & & 1 \\
\hline It got me engaged with research during the lockdown & & & 1 \\
\hline It would be nice to get tips for navigating the online platform & & & 1 \\
\hline
\end{tabular}

There were four comments in Table 10 over the three years that mentioned either drawing or doodling. In order to capture participants' thoughts on doodling more directly, regarding the most recent year of the HeNReG meetings, an additional question was added to the feedback form: What are your thoughts on doodling aspect of the HeNReG experience? The two most common responses that participants provided were: (1) It helps me, and (2) I loving doodling. There were only two people who mentioned they did not doodle. This very positive response to doodling was unexpected as, in reality, only a few people doodled during the 2020/21 year. Yet, regardless of whether they themselves contributed their doodles, they felt that the doodling was valuable, either in helping them directly in some way or because of a love they had for doodling. These responses provided support for continuing to included doodling as part of the group's activities in the years to follow. The responses by themes are provided in Table 11. 
Table 11. Themes in Responses Provided on the April Feedback Forms of the Academic Year in Answer to What Are Your Thoughts on the Doodling Aspect of the HeNReG Experience? For the Academic Year When the Question Was Included on the Feedback Form in Order of Receipt from Participants.

\begin{tabular}{cc}
\hline Number & 2020/21 Themes in Responses to Question about Doodling \\
\hline 2 & I do not doodle \\
2 & Gives me something to do \\
1 & I get carried away with doodling sometimes \\
6 & It helps me \\
4 & I love doodling \\
1 & Some of them look super amazing! \\
2 & Great aspect \\
\hline
\end{tabular}

* Feedback is provided by 18 rather than 20 participants as one group member had left the group to concentrate on his research by the time feedback was requested in the second term and another researcher did not return the form.

\section{Discussion}

The results comparing the three most recent years of the HeNReG meetings have demonstrated that in a group that is free to participants, voluntary, egalitarian and both geographically and by discipline diverse, there was little change in participant behaviour with respect to responding to writing prompts and the number of questions and responses provided by participants when the COVID-19 limitations were imposed and the group was moved entirely online. What did change was a decrease in participants' response to everyone in the group in comparison with when response to everyone was a practice maintained and encouraged at the in-person meetings before COVID-19. An even more significant change was the decrease in number of doodles created and posted to the private Facebook group. Interesting to note is that, in the feedback provided by group members in each year, the group as a whole was either unaware of these changes to how the group functioned or did not consider the changes important to mention as feedback. Still to be considered is in what way these decreases in participation actually mattered to the function of this specific form of academic meeting as a result of the pandemic.

\subsection{COVID-19 Limitations on the HeNReG}

From the time of the lockdown on 12 March 2020 to the end of the 2020/21 year of the HeNReG meetings, 28 April 2021, there was significant change regarding information about the dire conditions with respect to COVID-19 regarding morbidity and mortality. The information pertaining to the pandemic could be very concerning, this is especially so for those working in health care who were members of the HeNReG. Until vaccines were able to be administered to the public beginning December 2020 [81,82], there was a high level of uncertainty regarding the continued health of any one individual and of society as a whole.

It is for this reason it was unexpected that the group behaviour would be affected so minimally with respect to COVID-19. If not for a few group members having to stop attending as the weeks went on as a result of their responsibilities as health care providers, and others mentioning their interest in the pandemic ending when asked directly, there would have been no way to tell from the behaviour or responses that a pandemic was influencing the lives of participants so greatly.

\subsection{Choice of Online Platform}

Based on the last three years' worth of data regarding participation in the HeNReG, it evident the preference for group members in participation is asynchronous. As such, it calls into question the view that synchronous meetings are the gold standard, giving additional reason why a videoconferencing platform, like the popular Zoom, may not be the optimal choice for a meeting, such as the HeNReG, that focuses on both written and drawn replies. 
Why synchronous meetings are not preferred appears to have little relationship to the limitations imposed by COVID-19. Although group members who had attended the in-person meetings in the past missed the collegiality offered, when given the choice to attend the private Facebook meetings synchronously, most opted regularly to access the private Facebook group on their own time. This result was observed in each of the three years.

However, in making this choice to attend asynchronously, group members were not provided with similar resources in their participation. The result of this was most evident in the majority of group members choosing not to doodle.

The private Facebook group retained the advantage of providing an online space where all questions, responses and drawings could be posted in a permanent chronological order by the name of the person posting. When members prefer to join the discussion asynchronously, these are important online features to helping them navigate the group.

\subsection{Academic Meeting Features}

The results of this specific academic meeting directly pertain to the particular structure upheld for the HeNReG. It is a group based on self-directed learning, team mindfulness and democratically run meetings. How this overarching structure affected the outcome of each of the three years and, most specifically, whether the design of the group was altered as a result of COVID-19 is to be considered.

\subsubsection{Self-Directed Learning}

COVID-19 limitations had an effect on the self-directed learning of group members. Agency and activity are required in an autonomous learning environment, but when the meetings of the HeNReG went entirely online participants directed their learning less often to the each of the various ways of participating. Although there was no difference between responses to the prompts in comparison to pre-COVID-19, fewer participants chose to ask questions of others or to answer the questions others asked of them. The type of participation that decreased most obviously was the creation of drawings. Far fewer group members chose to submit doodles at the end of the meeting, yet their responses on the feedback form do not indicate any change in their interest in creating doodles. In this respect, group members seemed unaware that their self-directed learning had decreased significantly in this regard.

It is unclear whether this reduction in certain types of self-directed learning endeavours is a result of moving the group's activities entirely online, the restrictions brought on by COVID-19, or both. However, one study of self-directed learning after learning moved to online networks also found that under these conditions more participants watch what others do rather than participate directly, calling these silent participants "lurkers" [83]. In a further study of 846 participants regarding self-directed online learning, the decrease in synchronous participation evident with the HeNReG was also found with a decrease of more than half of the original number of synchronous participants by the end of the 40 sessions of weekly meetings [84]. In other words, moving the group online may have been sufficient reason for these changes in synchronous participation and COVID-19 was merely the catalyst to this change in the meetings' platform.

\subsubsection{Team Mindfulness}

Team mindfulness, as a flexible manner of interacting with team members where group participants are actively engaged in the present, notice new things and are sensitive to the context in which new information comes to the attention of the group [85], was a prominent feature of the HeNReG meetings during the time when the group met synchronously in person. Then, each participant would listen to others read their response to the prompt and provide them with a question the reader answered to further enrich what they had written. During this time, as people waited to answer questions, they were able to make use of the art resources available and doodled. Once the group moved entirely online, there was little 
meaning to team mindfulness-participants, even when engaging with others, did so as individuals rather than as a mindful team.

Whether the limitations imposed by COVID-19 are a cause of these more individuallyfocused results of group members is at issue. Research into the effect on team mindfulness resulting from a move to online meetings indicates that the virtual quality of the meeting in itself is sufficient to demonstrate this outcome [86]. In this regard, communication among virtual team members is seen to resemble multiple monologues where team members concentrate on providing what they know rather than dialogues where they share information in relation to considering the contributions of others.

This loss of team mindfulness in relation to moving to an online platform is particularly troubling with respect to the function of the HeNReG. The aim of the HeNReG is to reduce researchers' depression and/or anxiety with respect to their role as researchers, yet it is team mindfulness which has been recognized as a necessary ingredient to positive psychological, physiological and performance changes in work-related teams [87].

\subsubsection{Democratic Meetings}

The collegiality necessary to reduce depression and anxiety in researchers has been identified as best served by democratic meetings. Action research is the umbrella term for activities intended to foster change through recurring cycles of action and reflection [88]. In this regard, how the HeNReG meetings are constructed represents a form of action research. This type of research demands collaborative interaction among various perspectives with the democratic meeting at the heart of the effort.

Although the composition of HeNReG members retained its diversity once the group no longer met in person, the democratic nature of the meetings was reduced. Those who were directly involved with health care delivery were greatly affected by their duties related to COVID-19. The group lost more than one member during the year as a result of their lack of time to devote to anything but their job pertaining to COVID-19. As such, the diversity of the group was reduced directly as a result of COVID-19.

Once the group moved entirely online, another consequence was that group members no longer had access to common art resources available to doodle-likely an important reason why doodling dropped off significantly under this condition. Democracy in meetings, in this regard, does not only involve the diversity of participation. It also includes equal access to resources. When access is not equal, it has been found that group trust and cooperation is diminished [89]. A lack of trust causes problems as group members are less likely to participate when their expectation of social exchange is not met [90]. It may be that a lack of trust developed among the researchers once they could no longer expect to receive questions from all participants and they were less inclined to answer every question they received. Mutual trust is recognized as necessary for equality of relationships [91]. Without equality of relationships, the meeting loses its claim to being democratic.

\section{Conclusions}

The purpose of this study was to determine to what extent the results of the years that the Health Narratives Research Group met in person could be compared with changes in how the group functioned once the meetings were required to be online as a result of limitations to academic meetings imposed from the COVID-19 pandemic. Given that the manner in which the group functions has evolved since the group (as sponsored by the Department of Psychiatry) began in 2015, it was determined that the only years comparable were the three most recent-2018/19, 2019/20 and 2020/21. Of these, the synchronous meetings of the first year were conducted entirely in person. During the next year, the meetings were in person until after 12 March 2021 when all academic meetings were required to be online. For the final year, all meetings were online. In comparing the number of participants-synchronous, asynchronous and in total-it was found that there was little change in participation moving the group online during COVID-19. The change in participation that was found concerned the number of doodles produced. Synchronous 
meetings online coincided with significantly fewer doodles produced. Similarly, the number of questions asked and answered in each of the three years was comparable although fewer people were involved in asking more questions. These changes with respect to doodles and the number of different participants asking and answering questions were, for the most part, not recognized by participants as reported in the feedback forms. In examining the written responses on the feedback forms, the comments from one year differed very little from those of another. The success of the group in participant satisfaction was both consistent and high.

Nevertheless, regardless of its obviousness to participants, there were substantial differences in how the group operated once its synchronous meetings moved online. These changes were with respect to three aspects: self-directed learning, team mindfulness and democratic meetings. Once the synchronous meetings were online, fewer group members asked and answered questions, affecting both the self-direction of participants and their team mindfulness. As the equality among members with respect to their type of attendance changed, so too did the democratic nature of the HeNReG meetings. In relation to the philosophy of the HeNReG, there is a landscape of truth in which participants situate themselves and how participants related in the landscape had been modified.

The point of the HeNReG in holding meetings is for each participant to create routes from where they are in the landscape to where others reside with respect to their research related to health. Analogously, what changed when the group was required to meet only online was a reduction in routes participants created to other researchers. In other words, participants retained their ability (and perhaps even enhanced it) to describe where they were located in this theoretical landscape. However, what they did not do as much as when the group met in person was venture out into the landscape to meet up with others. Interestingly, what happened with respect to sheltering at home in the physical sense as a result of COVID-19 lockdowns also was seen to happen figuratively in the landscape of truth. Participants were less trusting than they were during in-person meetings of venturing into the landscape and finding connections between their research at that of others. Whether COVID-19, with respect to feelings of isolation and worry about the mortality and morbidity of the pandemic, is the reason for this reluctance to develop research-related routes to others in the landscape of truth or it is just the fact of moving all synchronous meetings online is the question.

\subsection{Limitations to the Research Method}

In assessing the suitability of the private Facebook group to maintain the philosophy and practices of the HeNReG as a result of COVID-19, this was a study undertaken historically. As such, during the years that the HeNReG was ongoing it was not the intention of the group to make this analysis. Once the comparative data were available, the study could be undertaken retrospectively. Consequently, there are limitations to the type of data collected.

The participants' evaluation of the group through the feedback forms could have been additionally direct and relevant had a feedback form been used that was unique to the group rather than employing the one used by the other offerings through the Department of Psychiatry. In trying to maintain the HeNReG's connection with the Health, Arts and Humanities program, details that would have been relevant to this historical study were left unexplored. There were only three questions on this common form that permitted written replies: How was the group valuable to you as a researcher? How might the HeNReG be of help to you in the future? Do you have other thoughts/comments on your experience as a participant in the HeNReG this term, especially as a result of COVID-19? Each of these questions directs the respondent to a particular way of answering the question, yet, can be broadly interpreted. These questions could have been more direct to assess the specific intention of the group.

With respect to the first question, the real interest was whether or not participants believed the group helped decrease their anxiety and depression with respect to their 
research - this was the value that the HeNReG was intended to create. Regarding the second question, there are many ways participants could interpret "help" and "future". What was important to assessing the HeNReG was whether participants thought the ordered question asking devised for this group was a method they might use when experiencing depression and/or anxiety with respect to their research work. Finally, the inclusion of "especially as a result of COVID-19" at the end of the vague question requesting any additional thoughts predisposed respondents to consider this question as something they likely had not given thought to before the question was posed. This was in contrast to directly asking participants how COVID-19 affected their research related to health. Furthermore, as diversity of the group was an important aspect of the HeNReG, it would have been relevant for the feedback forms to have an additional question asking how important group diversity was to the researcher in attending the HeNReG. Given that the answers provided by respondents to the feedback form were not as relevant to the intentions of the HeNReG, consideration has to be given to whether maintaining the same feedback form as other offerings in the Health, Arts and Humanities Program serves an important function that should be maintained or a form more relevant to the HeNReG should be developed and used.

In conducting this research historically, certain points were not investigated as a result of their lack of representation through the data. The examples of things not investigated were: (1) the reason for the lessening of participation towards the end of the second term in each year reported, (2) whether fewer people began to attend synchronously in 2021 after the first few weeks because they were not getting questions from many participants, and (3) why participants felt there was less participation once the group moved online.

The major limitation of this study is that both the quantitative and qualitative analysis provided were unable to identify COVID-19 and online participation as independent variables. On the other hand, the research that has been conducted on moving synchronous meetings online has found that decreasing of self-direction through decreasing team mindfulness, in becoming a monologue rather than a dialog, occurs regardless of other limitations [40]. In this regard, it would seem that if a decision had been made to move the group online pre-COVID-19 a similar result would have been noted. Nevertheless, it is unclear in what way the extent of reluctance to include others' perspectives with respect to self-reflection on research related to health was affected by the COVID-19 pandemic.

\subsection{Limitations to Private Facebook Groups}

One of the reasons for the difficulties in continuing with the aim of the HeNReGparticipants developing routes to other researchers regarding these researchers' understanding of their work-is that to enrich self-reflection on one's own research is in the nascence of online platforms. Although, for the purpose of the HeNReG, private Facebook groups were judged to be more effective than Zoom, these private Facebook groups have limitations in three main areas.

The first limitation is the search function on these private Facebook groups for specific entries is imprecise- a search for an exact phrase often produces results that include other entries that have similar information and misses some preferred entries. This disadvantage was evident when the data were being gathered for this study. This is a problem because it means that, although the private Facebook group is searchable by person entries, it is not reliable. Consequently, this hinders the ability of researchers to use the private Facebook group to ask questions of particular researchers asynchronously.

A second constraint is that the private Facebook group does not include a tool for creating surveys of group participants. In order to create and analyze the feedback forms for the HeNReG twice a year, Google forms [92] was used. Once the form was designed and ready to be completed, the facilitator attached the form to a message sent by Messenger to each of the HeNReG participants. If Facebook included the creation of feedback forms for its private groups and automatically sent these forms to all group members, this would make the private Facebook group not only a method of archiving academic meetings it 
would expand the idea of a meeting to include methods of group evaluation-a necessary ingredient of in what makes a meeting academic - and could permit group members to conduct their own research on the group for developing these routes in the landscape of truth.

The third limitation is that whatever physical resources were provided to participants in person are lost when academic meetings move online to a private Facebook group. Although Zoom, beyond private Facebook groups, is able to provide the ability to share screens during meetings, in a group like the HeNReG that depends on the sharing of art resources, there is currently no online program available that permits synchronous meetings where art materials can be shared and only an avatar of the participant created by the participant is visible onscreen. In this respect, what is needed to be developed for online platforms for synchronous meetings to provide a similar experience to that of in-person meetings is for a virtual meeting space to be created into which a personally relevant avatar can move around naturally and be seen by all participants to make use of resources provided in the space.

An online platform similar to Kumospace [93], where small real-time videos of participants act as avatars to meet and explore in a designed space while clicking on items to attach to their video, is a promising direction. A similar platform using non-personally invasive avatars is currently being developed by the Harvard Graduate School of Design [94]. However, problems still to be overcome are the ability to create a preferred avatar (rather than depending on a program-selected one or a video revealing self and work space) and actually using the virtual resources to create the type of results with which participants would be satisfied in a way similar to in-person meetings. These are both still to be solved. In the regard, the concern is to make online meetings more like a video game in which participants can interact and create (similar to Animal Crossing [95] or Minecraft [96]) in a way that is relevant to the research interest of the participant rather than the game; somewhat similar to the gamification of ChemDraw, a molecule speed-drawing tournament [97]. Furthermore, including the capacities available from a private Facebook group to permit participation to be stored through writing by group members, rather that clicking on pre-determined questions and answers, is still to be solved.

One result of COVID-19 that would not have occurred, with respect to moving a group like the HeNReG online, had the pandemic not necessitated a lockdown, is that potential participants have as a result all learned how to attend academic meetings online and online meetings have become the standard. As such, the need to make synchronous online academic meetings more user friendly, less personally invasive, visually attractive and resource providing is the direction that online platforms should evolve if online academic meetings are to provide a similar type of experience to the one previously provided by in-person meetings. For academic meetings intended to be self-directed, team mindful and conducted democratically, the future development of these types of online platforms is imperative if the landscape of truth that is to be of use to health researchers in decreasing their depression and anxiety while providing a structure for continuing their health-related research throughout their academic careers.

\subsection{Contribution of this Research}

Digital literacy is the aim in choosing an online platform. Much recent work has been done to compare Zoom with other online video conference platforms during COVID19 for use in academic meetings [98-101] — there has been limited research investigating the private Facebook groups for academic meetings at any time [102-105]. The lack of research on private Facebook groups is unexpected, as written work-fundamental to the private Facebook group - is the mainstay of successful academic meetings and most closely aligned with their intention [106]. This report will reduce this research gap by adding to the literature on private Facebook groups.

However, it should be noted, a report was written by this author a year ago on the effect of switching to the online platform of a private Facebook group mid-year for the 
2019-2020 academic meetings [104]. At the time this report was written, an investigation into previous peer reviewed studies on the use of private Facebook groups for academic meetings did not reveal any that had been conducted. Two articles have since have been identified $[102,103]$ that were published pre-COVID-19. Following the publication of the report of last year, only one additional paper on this topic has been become available [105]. As a result, this account of the effect of COVID-19 lockdown on a full academic year for one particular academic meeting retains its importance to fill the research gap currently evident with respect to the use of private Facebook groups for academic meetings.

As COVID-19 restrictions will remain in effect in the Department of Psychiatry at this university during the 2021-2022 academic year, requiring the continuation of online meetings [107], the results of this research maintain their relevance for this university and to others preserving online teaching [108], especially in regard to self-directed learning, team mindfulness and democratic meetings.

\subsection{Recommendations}

For narratives groups concerned with encouraging written replies and/or visual creations this assessment has indicated that private Facebook groups are a more relevant choice at the present time for conducting online meetings, especially during COVID-19, compared with video conferencing platforms, like Zoom. Nevertheless, facilitators of such groups need to be attuned to improvements that are being made to social networking sites designed specifically for online meetings-Kumospace is an example. What is needed for such groups in an online meeting space is to replicate the functionality and reality offered with video game digital construction and, at the same time, offer storage functions for written responses that are easily set up, accessible, maintainable, searchable and testable. When such a platform is created, group trust in breaking down silos can be demonstrated and the online groups necessitated during COVID-19 lockdowns will have the ability to support self-directed learning, encourage team mindfulness and provide the democratic meeting structure necessary for the success of these groups.

Funding: This research received no external funding.

Institutional Review Board Statement: Not applicable.

Informed Consent Statement: Informed consent was obtained from all subjects involved in the study.

Data Availability Statement: Data are available on request due to privacy restrictions. The data presented in this study are available on request from the corresponding author. The data are not publicly available due to privacy restrictions expected by participants when they agreed to join the Health Narratives Research Group.

Acknowledgments: Thank you to Edward Shorter, Jason A. Hannah Professor in the History of Medicine, University of Toronto and to Allan Peterkin, Professor of Psychiatry and Family Medicine at the University of Toronto and director of the Health, Arts and Humanities Program, for their support of the Health Narratives Research Group.

Conflicts of Interest: The author declares no conflict of interest.

\section{References}

1. Daly-Grafstein, D.; Daly, P.; Gustafson, R. Resuming In-Person Classes under COVID-19: Evaluating Assigned Seating Protocols in Limiting Contacts at Postsecondary Institutions. medRxiv 2021. [CrossRef]

2. Gertler, M.S. To All Members of the U of T Community: RE: Cancellation of Classes and Delivery of Teaching through Other Means. Available online: https:/ / www.president.utoronto.ca/important-announcement-from-president-gertler-regarding-COVID-19 (accessed on 4 September 2021).

3. Ramphul, K.; Ramphul, Y.; Park, Y.; Lohana, P.; Dhillon, B.K.; Sombans, S. A comprehensive review and update on severe acute respiratory syndrome coronavirus 2 (SARS-CoV-2) and Coronavirus disease 2019 (COVID-19): What do we know now in 2021? Arch. Med. Sci.-Atheroscler. Dis. 2021, 6, e5-e13. [CrossRef] [PubMed]

4. World Health Organization (WHO). Timeline: WHO's COVID-19 Response. Available online: https://www.who.int/ emergencies / diseases/novel-coronavirus-2019/interactive-timeline\#! (accessed on 4 September 2021). 
5. COVID-19 Dashboard by the Center for Systems Science and Engineering (CSSE) at Johns Hopkins University (JHU). Available online: https: / / coronavirus.jhu.edu/map.html (accessed on 2 November 2021).

6. Tian, S.; Hu, N.; Lou, J.; Chen, K.; Kang, X.; Xiang, Z.; Chen, H.; Wang, D.; Liu, N.; Liu, D.; et al. Characteristics of COVID-19 infection in Beijing. J. Infect. 2020, 80, 401-406. [CrossRef] [PubMed]

7. Walker, A.; Pottinger, G.; Scott, A.; Hopkins, C. Anosmia and loss of smell in the era of COVID-19. BMJ 2020, $370, \mathrm{~m} 2808$. [CrossRef]

8. Viola, P.; Ralli, M.; Pisani, D.; Malanga, D.; Sculco, D.; Messina, L.; Laria, C.; Aragona, T.; Leopardi, G.; Ursini, F.; et al. Tinnitus and equilibrium disorders in COVID-19 patients: Preliminary results. Eur. Arch. Oto-Rhino-Laryngol. 2021, 278, 3725-3730. [CrossRef]

9. Hui, D.S.; Azhar, E.I.; Madani, T.A.; Ntoumi, F.; Kock, R.; Dar, O.; Ippolito, G.; Mchugh, T.D.; Memish, Z.A.; Drosten, C.; et al. The Continuing 2019-nCoV Epidemic Threat of Novel Coronaviruses to Global Health-The latest 2019 novel coronavirus outbreak in Wuhan, China. Int. J. Infect. Dis. 2020, 91, 264-266. [CrossRef]

10. Stevens, J.S.; King, K.L.; Robbins-Juarez, S.Y.; Khairallah, P.; Toma, K.; Alvarado Verduzco, H.; Daniel, E.; Douglas, D.; Moses, A.A.; Peleg, Y.; et al. High rate of renal recovery in survivors of COVID-19 associated acute renal failure requiring renal replacement therapy. PLOS ONE 2020, 15, e0244131. [CrossRef]

11. Nussbaumer-Streit, B.; Mayr, V.; Dobrescu, A.I.; Chapman, A.; Persad, E.; Klerings, I.; Wagner, G.; Siebert, U.; Christof, C.; Zachariah, C.; et al. Quarantine alone or in combination with other public health measures to control COVID-19: A rapid review. Cochrane Database Syst. Rev. 2020, 4, CD013574. [CrossRef]

12. Heffner, J.; Vives, M.-L.; FeldmanHall, O. Emotional responses to prosocial messages increase willingness to self-isolate during the COVID-19 pandemic. Pers. Individ. Differ. 2021, 170, 110420. [CrossRef]

13. Verma, B.K.; Verma, M.; Msc, V.K.V.; Abdullah, R.B.; Nath, D.C.; Khan, H.T.A.; Verma, A.; Vishwakarma, R.K.; Verma, V. Global lockdown: An effective safeguard in responding to the threat of COVID-19. J. Eval. Clin. Pract. 2020, 26, 1592-1598. [CrossRef]

14. Peterkin, A.; (University of Toronto, Toronto, ON, Canada). Personal communication, 12:39 p.m. 12 March 2020.

15. Peterkin, A.; (University of Toronto, Toronto, ON, Canada). Personal communication, 5:30 p.m. 12 March 2020.

16. Dennis, A.R.; George, J.F.; Jessup, L.M.; Nunamaker, J.F.; Vogel, D.R. Information technology to support electronic meetings. MIS Q. 1988, 12, 591-624. [CrossRef]

17. Astin, A.W. Student involvement: A developmental theory for higher education. J. Coll. Stud. Dev. 1999, 40, 518-529.

18. Kwon, O.; Min, D.; Geringer, S.; Lim, S.-K. Students perceptions of qualifications for successful social media. Acad. Mark. Stud. J. 2013, 17, 109-128.

19. Dede, C. Immersive interfaces for engagement and learning. Science 2009, 323, 66-69. [CrossRef]

20. Partridge, S.R.; Gallagher, P.; Freeman, B.; Gallagher, R. Facebook groups for the management of chronic diseases. J. Med. Internet Res. 2018, 20, e21. [CrossRef]

21. Weller, S. Using internet video calls in qualitative (longitudinal) interviews: Some implications for rapport. Int. J. Soc. Res. Methodol. 2017, 20, 613-625. [CrossRef]

22. Polin, L. Learning in dialogue with a practicing community. In Learner-Centered Theory and Practice in Distance Education; Duffy, T.M., Kirkley, J.R., Eds.; Lawrence Erlbaum Associates: Mahwah, NJ, USA, 2004; pp. 17-48.

23. McMillan, D.W.; Chavis, D.M. Sense of community: A definition and theory. J. Community Psychol. 1986, 14, 6-23. [CrossRef]

24. Laverack, G. The challenge of behaviour change and health promotion. Challenges 2017, 8, 25. [CrossRef]

25. Medley-Rath, S. Using Facebook Secret Groups for Qualitative Data Collection. Qual. Rep. 2019, 24, 1765-1777. [CrossRef]

26. Lam, L. An innovative research on the usage of Facebook in the higher education context of Hong Kong. Electron. J. ELearn. 2012, 10, 378-386.

27. Boyd, D.; Hargittai, E. Facebook privacy settings: Who cares? First Monday 2010, 15. [CrossRef]

28. Wang, Q.; Woo, H.L.; Quek, C.L.; Yang, Y.; Liu, M. Using the facebook group as a learning management system: An exploratory study. Br. J. Educ. Technol. 2012, 43, 428-438. [CrossRef]

29. Raynes-Goldie, K. Aliases, creeping, and wall cleaning: Understanding privacy in the age of Facebook. First Monday 2010, 15. [CrossRef]

30. Vaas, L. Facebook Finally Changes Real-Name Policy. Naked Security. 2015. Available online: https://nakedsecurity.sophos. com/2015/11/03/facebook-finally-changes-real-name-policy/ (accessed on 6 September 2021).

31. Green, T.; Wilhelmsen, T.; Wilmots, E.; Dodd, B.; Quinn, S. Social anxiety, attributes of online communication and self-disclosure across private and public facebook communication. Comput. Hum. Behav. 2016, 58, 206-213. [CrossRef]

32. Castelli, F.R.; Sarvary, M.A. Why students do not turn on their video cameras during online classes and an equitable and inclusive plan to encourage them to do so. Ecol. Evol. 2021, 11, 3565-3576. [CrossRef]

33. Reich, J.; Buttimer, C.J.; Coleman, D.; Colwell, R.D.; Faruqi, F.; Larke, L.R. What's Lost, What's Left, What's Next: Lessons Learned from the Lived Experiences of Teachers during the 2020 Novel Coronavirus Pandemic. Available online: Edarxiv.org/8exp9 (accessed on 6 September 2021).

34. Yoon, M.; Lee, J.; Jo, I.-H. Video learning analytics: Investigating behavioral patterns and learner clusters in video-based online learning. Int. High. Educ. 2021, 50, 100806. [CrossRef]

35. Adair, H.E.; Slattery, J.M. Cameras in Zoom: Should They Be On? Hand in Hand 2021. Available online: https: / / handinhandclarion.wordpress.com/2021/01/23/cameras-in-zoom-should-they-be-on/ (accessed on 6 September 2021). 
36. Bailenson, J.N. Nonverbal Overload: A Theoretical Argument for the Causes of Zoom Fatigue. Technol. Mind Behav. 2021, 2. [CrossRef]

37. Hacker, J.; vom Brocke, J.; Handali, J.; Otto, M.; Schneider, J. Virtually in this together-How web-conferencing systems enabled a new virtual togetherness during the COVID-19 crisis. Eur. J. Inf. Syst. 2020, 29, 563-584. [CrossRef]

38. Reinholz, D.L.; Andrews, T.C. Breaking Down Silos Working Meeting: An Approach to Fostering Cross-Disciplinary STEM-DBER Collaborations through Working Meetings. CBE Life Sci. Educ. 2019, 18, mr3. [CrossRef]

39. Kitts, R.L.; Christodoulou, J.; Goldman, S. Promoting Interdisciplinary Collaboration: Trainees Addressing Siloed Medical Education. Acad. Psychiatry 2011, 35, 317-321. [CrossRef]

40. Colgan, D.; Christopher, M.; Bowen, S.; Brems, C.; Hunsinger, M.; Tucker, B.; Dapolonia, E. Mindfulness-based Wellness and Resilience intervention among interdisciplinary primary care teams: A mixed-methods feasibility and acceptability trial. Prim. Health Care Res. Dev. 2019, 20, E91. [CrossRef]

41. Wilson, D.E. Moving toward democratic-transformational leadership in academic libraries. Libr. Manag. 2020, 41, 731-744. [CrossRef]

42. Knowles, M.S. Innovations in teaching styles and approaches based upon adult learning. J. Educ. Soc. Work 1971, 8, 32-39. [CrossRef]

43. Garrison, D.R. Self-Directed Learning: Toward a Comprehensive Model. Adult Educ. Quart. 1997, 48, 18-33. [CrossRef]

44. Taylor, D.C.M.; Hamdy, H. Adult learning theories: Implications for learning and teaching in medical education: AMEE Guide No. 83. Med. Teach. 2013, 35, e1561-e1572. [CrossRef]

45. Bandura, A. Social Foundations of Thought and Action: A Social Cognitive Theory; Prentice-Hall: Englewood Cliffs, NJ, USA, 1986.

46. Doo, M.Y.; Bonk, C.J.; Kim, J. An investigation of under-represented MOOC populations: Motivation, self-regulation and grit among 2-year college students in Korea. J. Comput. High. Educ. 2021, 33, 419-440. [CrossRef]

47. Fischer, G.; Scharff, E. Learning technologies in support of self-directed learning. J. Interact. Media Educ. 1998, 2. [CrossRef]

48. Knowles, M.S. Andragogy: Adult learning theory in perspective. Community Coll. Rev. 1978, 5, 9-10. [CrossRef]

49. Sahu, P. Closure of universities due to coronavirus disease 2019 (COVID-19): Impact on education and mental health of students and academic staff. Cureus 2020, 12, e7541. [CrossRef]

50. Mezirow, J. A critical theory of self-directed learning. In Self-Directed Learning: From Theory to Practice; New Directions for Continuing Education \#25; Brookfield, S., Ed.; Jossey-Bass: San Francisco, CA, USA, 1990.

51. Liu, S.; Xin, H.; Shen, L.; He, J.; Liu, J. The Influence of Individual and Team Mindfulness on Work Engagement. Front. Psychol. 2020, 10, 2928. [CrossRef]

52. Yu, L.; Zellmer-Bruhn, M. Introducing Team Mindfulness and Considering its Safeguard Role Against Conflict Transformation and Social Undermining. Acad. Manag. 2017, 61, 324-347. [CrossRef]

53. Rupprecht, S.; Koole, W.; Chaskalson, M.; Tamdjidi, C.; West, M. Running too far ahead? Towards a broader understanding of mindfulness in organisations. Curr. Opin. Psychol. 2019, 28, 32-36. [CrossRef] [PubMed]

54. Maslach, C.; Leiter, M.P. Understanding the burnout experience: Recent research and its implications for psychiatry. World Psychiatry 2016, 15, 103-111. [CrossRef] [PubMed]

55. Bazeley, P. Conceptualising research performance. Stud. High. Educ. 2010, 35, 889-903. [CrossRef]

56. Liu, C.; Wang, L.; Qi, R.; Wang, W.; Jia, S.; Shang, D.; Shao, Y.; Yu, M.; Zhu, X.; Yan, S.; et al. Prevalence and associated factors of depression and anxiety among doctoral students: The mediating effect of mentoring relationships on the association between research self-efficacy and depression/anxiety. Psychol. Res. Behav. Manag. 2019, 12, 195-208. [CrossRef]

57. Eisenberg, D.; Gollust, S.E.; Golberstein, E.; Hefner, J.L. Prevalence and correlates of depression, anxiety, and suicidality among university students. Am. J. Orthopsychiatry 2007, 77, 534-542. [CrossRef]

58. Sadiq, M.S.; Morshed, N.M.; Rahman, W.; Chowdhury, N.F.; Arafat, S.M.Y.; Mullick, M.S.I. Depression, Anxiety, Stress among Postgraduate Medical Residents: A Cross sectional Observation in Bangladesh. Iran. J. Psychiatry 2019, 14, 192. [CrossRef]

59. Fox, M.F. Publication Productivity among Scientists: A Critical Review. Soc. Stud. Sci. 1983, 13, 285-305. [CrossRef]

60. Edgar, F.; Geare, A. Factors influencing university research performance. Stud. High. Educ. 2013, 38, 774-792. [CrossRef]

61. Huffman, M. Advancing the practice of health coaching differentiation from wellness coaching. Workplace Health Saf. 2016, 64, 400-403. [CrossRef]

62. Improving Health: Changing Behaviour. NHS Health Trainer Handbook. Available online: https://uwe-repository.worktribe. com/output/1011599/improving-health-changing-behaviour-nhs-health-trainer-handbook (accessed on 6 September 2021).

63. Brew, A. Teaching and research: New relationships and their implications for inquiry-based teaching and learning in higher education. High. Educ. Res. Dev. 2012, 31, 101-114. [CrossRef]

64. Van den Besselaar, P.; Heimeriks, G. Disciplinary, Multidisciplinary, Interdisciplinary-Concepts and Indicators. Available online: https:/ / www.researchgate.net/profile/Peter_Van_Den_Besselaar/publication/267939164_Disciplinary_Multidisciplinary_ Interdisciplinary_-Concepts_and_Indicators/links/546528810cf2f5eb17ff37c8/Disciplinary-Multidisciplinary-InterdisciplinaryConcepts-and-Indicators.pdf (accessed on 6 September 2021).

65. Moen, T. Reflections on the narrative research approach. Int. J. Qual. Methods 2006, 5, 56-69. [CrossRef]

66. Google Maps. What is Street View? September 2021. Available online: https://www.google.com/streetview / (accessed on 6 September 2021).

67. Wojciech, M. Truth and phenomenological landscape of perception. Respectus Philol. 2012, 22, 11-20. 
68. McDaugall, M.; Beattie, R.S. Peer Mentoring at Work: The Nature and Outcomes of Non-Hierarchical Developmental Relationships. Manag. Learn. 1997, 28, 423-437. [CrossRef]

69. Richins, M.T.; Barreto, M.; Karl, A.; Lawrence, N. Empathic responses are reduced to competitive but not non-competitive outgroups. Soc. Neurosci. 2019, 14, 345-358. [CrossRef]

70. Wilson, J.T.; Bauer, P.J. Prompt-facilitated learning: The development of unprompted memory integration and subsequent self-derivation. Mem. Cogn. 2021, 49, 1473-1487. [CrossRef]

71. Wilson, J.T.; Bauer, P.J. Correction to: Prompt-facilitated learning: The development of unprompted memory integration and subsequent self-derivation. Mem. Cogn. 2021, 49, 1488-1489. [CrossRef]

72. Slade, D.; Martin, A.; Watson, G. Practitioner auto-ethnography: Self-reflection for discovery and deeper understanding. Curric. Stud. Health Phys. Educ. 2020, 11, 252-264. [CrossRef]

73. Uttal, L.; Gloria, A.M. Developing Reflective Self-Awareness in Online Undergraduate Courses. Int. J. E-Learn. 2021, $20,199-222$.

74. Jacob, S.G.; Willits, F.K. Objective and Subjective Indicators of Community Evaluation: A Pennsylvania Assessment. Soc. Ind. Res. 1994, 32, 161-177. [CrossRef]

75. Identity and Story: Creating Self in Narrative; McAdams, D.P.; Josselson, R.; Lieblich, A. (Eds.) American Psychological Association: Washington, DC, USA, 2006. [CrossRef]

76. Baweja, P.; Kono, S.; Beniwal, A.; Baweja, P.; Spracklen, K. (Eds.) Doodling: A positive creative leisure practice. In Positive Sociology of Leisure. Leisure Studies in a Global Era; Palgrave Macmillan: Cham, Switzerland, 2020; pp. $333-349$.

77. Bolstrom, R.P.; Anson, R.; Jessup, L.M.; Valacich, J.S.; Clawson, V.K. (Eds.) Group facilitation and group support systems. In Group Support Systems: New Perspectives; Macmillan: New York, NY, USA, 1993; pp. 146-168.

78. Endler, N.S.; Denisoff, E.; Rutherford, A. Anxiety and depression: Evidence for the differentiation of commonly cooccurring constructs. J. Psychopathol. Behav. Assess. 1998, 20, 149-171. [CrossRef]

79. Starr, L.R.; Hammen, C.; Phillips Connolly, N.; Brennan, P.A. Does relational dysfunction mediate the association between anxiety disorders and later depression? Testing an interpersonal model of comorbidity. Depress. Anxiety 2014, 31, 77-86. [CrossRef] [PubMed]

80. Nash, C. Doodling as a Measure of Burnout in Healthcare Researchers. Cult. Med. Psychiatry 2021, 45, 565-598. [CrossRef] [PubMed]

81. Miles, D.K.; Heald, A.H.; Stedman, M. How fast should social restrictions be eased in England as COVID-19 vaccinations are rolled out? Int. J. Clin. Pract. 2021, 75, e14191. [CrossRef]

82. Swan, D.A.; Bracis, C.; Janes, H.; Moore, M.; Matrajt, L.; Reeves, D.B.; Burns, E.; Donnell, D.; Cohen, M.S.; Schiffer, J.T.; et al COVID-19 vaccines that reduce symptoms but do not block infection need higher coverage and faster rollout to achieve population impact. Sci. Rep. 2021, 11, 15531. [CrossRef]

83. Kop, R.; Fournier, H. New dimensions to Self-Directed Learning in an Open Networked Learning Environment. Int. J. Self-Dir. Learn. 2010, 7, 2-20.

84. Fournier, H.; Kop, R.; Guillaume, D. Challenges to Research in MOOCS. J. Online Learn. Teach. 2014, 10, 1-15.

85. Selart, M.; Schei, V.; Lines, R.; Nesse, S. Can Mindfulness be Helpful in Team Decision-Making? A Framework for Understanding How to Mitigate False Consensus. Eur. Manag. Rev. 2020, 17, 1015-1026. [CrossRef]

86. Curtis, A.M.; Dennis, A.R.; McNamara, K.O. From Monologue to Dialogue: Performative Objects to Promote Collective Mindfulness in Computer-Mediated Team Discussions. MIS Q. 2017, 41, 559-581. [CrossRef]

87. Johnson, K.R.; Park, S.; Chaudhuri, S. Mindfulness training in the workplace: Exploring its scope and outcomes. Eur. J. Train. Dev. 2020, 44, 341-354. [CrossRef]

88. Dickens, L.; Watkins, K. Action Research: Rethinking Lewin. Manag. Learn. 1999, 30, 127-140. [CrossRef]

89. Cozzolino, P.J. Trust, cooperation, and equality: A psychological analysis of the formation of social capital: Trust, cooperation, and equality. Br. J. Soc. Psychol. 2011, 50, 302-320. [CrossRef]

90. Haas, D.F.; Deseran, F.A. Trust and Symbolic Exchange. Soc. Psychol. Q. 1981, 44, 3-13. [CrossRef]

91. Eisenstadt, S.N.; Roniger, L. Patrons, Clients, and Friends: Interpersonal Relations and the Structure of Trust in Society; Cambridge University Press: London, UK, 1984; p. 2.

92. Google. Get Started with Google Forms. Google for Education. 2021. Available online: https://Educ.google.com/intl/ALL_ca/ teacher-center/products / forms/?modal_active=none (accessed on 4 October 2021).

93. Kumospace. The Best Place to Host on the Internet. Kumospace. 2021. Available online: https://www.kumospace.com (accessed on 3 October 2021).

94. Guida, G.; Tian, R.; Dong, Y. Multimodal Virtual Experience for Design Schools in the Immersive Web. In Towards a New, Configurable Architecture, Proceedings of the 39th eCAADe Conference, Novi Sad, Serbia, 8-10 September 2021; Stojakovic, V., Tepavcevic, B., Eds.; Architexturez Research: Kochi, Kerala, India, 2021; Volume 1, pp. 415-424.

95. Amiibo. Welcome to Animal Crossing. Nintendo. 2021. Available online: https://www.animal-crossing.com (accessed on 4 October 2021).

96. Microsoft. Welcome to Minecraft. Minecraft. 2021. Available online: https://www.minecraft.net/en-us (accessed on 4 October 2021). 
97. Fontana, M.T. Gamification of ChemDraw during the COVID-19 Pandemic: Investigating How a Serious, Educational-Game Tournament (Molecule Madness) Impacts Student Wellness and Organic Chemistry Skills while Distance Learning. J. Chem. Educ. 2020, 97, 3358-3368. [CrossRef]

98. Flores, M.A.; Gago, M. Teacher education in times of COVID-19 pandemic in Portugal: National, institutional and pedagogical responses. J. Educ. Teach. 2020, 46, 507-516. [CrossRef]

99. Dhawan, S. Online learning: A panacea in the time of COVID-19 crisis. J. Educ. Technol. Syst. 2020, 49, 5-22. [CrossRef]

100. Ali, W. Online and remote learning in higher education institutes: A necessity in light of COVID-19 pandemic. High. Educ. Stud. 2020, 10, 16-25. [CrossRef]

101. Boland, J.; Banks, S.; Krabbe, R.; Lawrence, S.; Murrary, T.; Henning, T.; Vandenberg, M. A COVID-19-era rapid review: Using Zoom and Skype for qualitative group research. Public Health Res. Pract. 2021, 1-9. [CrossRef]

102. Meishar-Tal, H.; Kurtz, G.; Pieterse, E. Facebook Groups as LMS: A Case Study. Int. Rev. Res. Open Distrib. Learn. 2012, 13, 33-48. [CrossRef]

103. Miron, E.; Ravid, G. Facebook Groups as an Academic Teaching Aid: Case Study and Recommendations for Educators. Educ. Technol. Soc. 2015, 18, 371-384.

104. Nash, C. Report on Digital Literacy in Academic Meetings during the 2020 COVID-19 Lockdown. Challenges 2020, 11, 20. [CrossRef]

105. Docimo, S.; Jacob, B.; Seras, K.; Ghanem, O. Closed Facebook groups and COVID-19: An evaluation of utilization prior to and during the pandemic. Surg. Endosc. 2021, 35, 4986-4990. [CrossRef]

106. Yunus, M.; Salehi, H. The Effectiveness of Facebook Groups on Teaching and Improving Writing: Students' Perceptions. Int. J. Educ. Inform. Technol. 2012, 1, 87-96.

107. Peterkin, A.; (University of Toronto, Toronto, ON, Canada). Personal communication, 12:06 p.m. 28 May 2021.

108. Benson, K. In Favour of Universal Design: The Argument for Continued Hybrid Online/In-Person Courses in the Wake of the COVID-19 Pandemic with a Focus on Students with Disabilities. SSRN 2021. [CrossRef] 